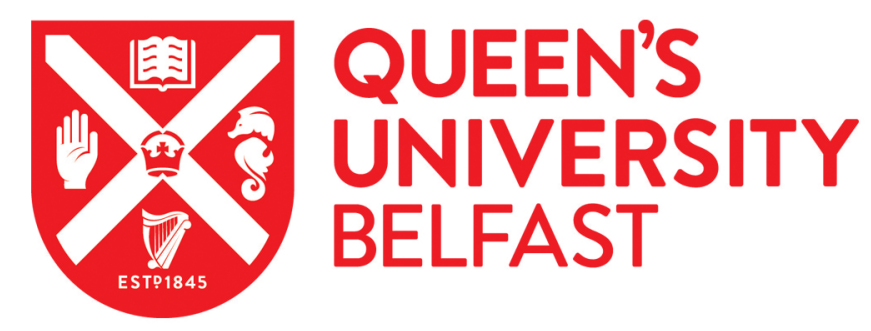

\title{
Determining the Presence of Scour around Bridge Foundations Using Vehicle-Induced Vibrations
}

\author{
Prendergast, L. J., Hester, D., \& Gavin, K. (2016). Determining the Presence of Scour around Bridge \\ Foundations Using Vehicle-Induced Vibrations. Journal of Bridge Engineering, [04016065]. \\ https://doi.org/10.1061/(ASCE)BE.1943-5592.0000931
}

Published in:

Journal of Bridge Engineering

Document Version:

Peer reviewed version

Queen's University Belfast - Research Portal:

Link to publication record in Queen's University Belfast Research Portal

Publisher rights

(C) 2016 American Society of Civil Engineers.

The final published version can be found at http://ascelibrary.org/doi/10.1061/\%28ASCE\%29BE.1943-5592.0000931

\section{General rights}

Copyright for the publications made accessible via the Queen's University Belfast Research Portal is retained by the author(s) and / or other copyright owners and it is a condition of accessing these publications that users recognise and abide by the legal requirements associated with these rights.

Take down policy

The Research Portal is Queen's institutional repository that provides access to Queen's research output. Every effort has been made to ensure that content in the Research Portal does not infringe any person's rights, or applicable UK laws. If you discover content in the Research Portal that you believe breaches copyright or violates any law, please contact openaccess@qub.ac.uk. 


\section{Abstract}

\title{
Determining the presence of scour around bridge foundations using vehicle-induced vibrations
}

\author{
Luke J. Prendergast, Ph.D. ${ }^{1, *}$, David Hester, Ph.D. ${ }^{2}$, Kenneth Gavin, Ph.D. ${ }^{3}$
}

Bridge scour is the number one cause of failure in bridges located over waterways. Scour leads to rapid losses in foundation stiffness and can cause sudden collapse. Previous research on bridge health monitoring has used changes in natural frequency to identify damage in bridge beams. The possibility of using a similar approach to identify scour is investigated in this paper. To assess if this approach is feasible, it is necessary to establish how scour affects the natural frequency of a bridge and is it possible to measure changes in frequency using the bridge dynamic response to a passing vehicle. To address these questions, a novel VehicleBridge-Soil Interaction (VBSI) model is developed. By carrying out a modal study in this model, it is shown that for a wide range of possible soil states, there is a clear reduction in the natural frequency of the first mode of the bridge with scour. Moreover, it is shown that the response signals on the bridge from vehicular loading are sufficient to allow these changes in frequency to be detected.

Keywords: Scour, Vibrations, Frequency, Soil Stiffness, Bridges, SHM

\footnotetext{
${ }^{1}$ School of Civil Engineering, University College Dublin, Belfield, Dublin 4, Ireland. Email luke.prendergast@ucdconnect.ie

${ }^{2}$ School of Planning, Architecture and Civil Engineering, Queen's University Belfast, University Road, Belfast, BT7 1NN, Northern Ireland, UK. Email d.hester@qub.ac.uk ${ }^{3}$ School of Civil Engineering, University College Dublin, Belfield, Dublin 4, Ireland. Email kenneth.gavin@ucd.ie

*Corresponding Author
} 
Bridge scour

Bridge scour is the term given to the excavation and removal of material from the bed and banks of rivers as a result of the erosive action of flowing water (Hamill 1999). Scouring of bridge foundations is the primary cause of failure of bridges in the United States (Briaud et al. 2001, 2005; Melville and Coleman 2000). One study of over 500 bridge failures which occurred between 1989 and 2000 in the US deemed flooding and scour to be the primary cause of 53\% of failures (Wardhana and Hadipriono 2003). Another review claims that over the past 30 years, 600 bridges in the US have failed due to scour problems (Briaud et al. 1999; Shirole and Holt 1991). As well as the risk to human life, these failures cause major disruption and economic losses (De Falco and Mele 2002). Lagasse et al. (1995) estimate that the average cost for flood damage repair of bridges in the United States is approximately $\$ 50$ million per annum. Scour is relatively difficult to predict and poses serious risks to the stability of vulnerable structures. It typically results in a loss in foundation stiffness that can compromise structural safety. With regard to scour, visual inspections involve the use of divers to inspect the condition of foundation elements (Avent and Alawady 2005). These types of inspections can be expensive and can have limited effectiveness as inspecting the condition of the foundation can be dangerous in times of flooding, when the risk of scour is highest. Due to the re-filling of scour holes as flood waters subside, visual inspections undertaken after a flood event may fail to detect the loss in stiffness resulting from scour as the backfilled material may be loose and therefore have significantly reduced strength and stiffness properties. Many mechanical and electrical instruments have been developed that aim to remotely detect the presence of scour. These include systems such as magnetic sliding collars, float-out systems (Briaud et al. 2011), radar systems (Anderson et al. 2007; Forde et al. 1999), vibration-based systems (Fisher et al. 2013; Zarafshan et al. 2012) and time-domain 
44 reflectometry (Yankielun and Zabilansky 1999; Yu 2009) among others. A comprehensive overview of the instrumentation available is given in Prendergast and Gavin (2014). The primary drawback of both visual inspections and the use of mechanical scour depth measuring instrumentation is that these typically cannot detect the distress experienced by a structure due to the development of a scour hole around the foundation. Monitoring changes in the modal properties of a structure can potentially provide insight into a structure's distress due to a scour hole. Some background on previous research into this is provided in the next section.

\section{Scour monitoring using structural dynamics}

The overall stiffness of a bridge is comprised of a combination of the mechanical properties of the structural elements (e.g. deck, piers, abutments) and the properties of the foundation soil. Detecting damage in a bridge superstructure by looking for changes in the dynamic response has received much attention in the literature (Abdel Wahab and De Roeck 1999; Doebling and Farrar 1996; Sampaio et al. 1999). Whilst scour will result in changes in the stiffness and therefore the dynamic response of a structure, research on detecting scour using vibration-based methods is relatively limited. In previous studies, properties such as natural frequency, mode shapes, mode shape curvature, covariance of acceleration signals and changes in the Root Mean Square (RMS) of acceleration signals have all been examined as possible indicators of scour (Briaud et al. 2011; Chen et al. 2014; Elsaid and Seracino 2014; Klinga and Alipour 2015).

Foti and Sabia (2011) describe a full-scale investigation undertaken on a five-span bridge where one pier was adversely affected by scour during a major flood in 2000. The modal parameters of the bridge deck spans (namely natural frequencies and mode shapes), were identified from traffic-induced vibrations before and after replacement of the pier. Most of 
the spans did not show a significant change. However, the span supported by the scoured pier did exhibit a lower frequency than the others. The pier itself was analysed in a different manner. It was recognised that scour affecting one side of the pier would result in asymmetric dynamic behaviour, therefore to detect this behaviour an array of accelerometers was placed along the foundation in the direction of flow. The method used to analyse the signals was the creation of a covariance matrix of the signals, whereby the diagonal terms of this covariance matrix coincide with the variances of single signals. The difference in magnitude of the variance along the foundation showed that scour could be detected using this methodology. Elsaid and Seracino (2014) describe a study undertaken into the effect of scour on the dynamic response of a scaled model of a coastal bridge supported by piles. Both laboratory testing and finite element modelling were undertaken. Horizontally displaced mode shapes showed significant sensitivity to scour progression due to the reduction in the flexural rigidity of the piles. Other indicators namely; mode shape curvature, flexibility-based deflection and curvature were also investigated. It was concluded that these methods each showed promise at detecting the location and extent of scour to varying degrees of accuracy. No soil-structure interaction was considered in the study by Elsaid and Seracino (2014). Briaud et al. (2011) describe a laboratory study into the effect of scour on the dynamic response of a model scale bridge with a span of $2.06 \mathrm{~m}$ and a deck width of $0.53 \mathrm{~m}$. Both shallow and deep foundations were tested in a large hydraulic flume. Fast Fourier transforms were used to obtain the frequency content of the acceleration signals measured in three directions for both foundation types, namely the flow direction, the traffic direction and the vertical direction. The ratio of Root-Mean Square (RMS) values of accelerations measured in two different directions (traffic/vertical, flow/traffic or flow/vertical) was also calculated to ascertain if it could be used as a scour indicator. The frequency response in the flow direction as well as the ratio of RMS values for flow/traffic showed the highest sensitivity to scour. A full-scale deployment 
of the methods by Briaud et al. (2011) on a real bridge proved unsuccessful due to a failure of the logging system and the high energy required to store and transmit acceleration data. It was concluded that accelerometers showed potential for detecting and monitoring scour but would require significant further research. Ju (2013) investigated the effect of soil-fluidstructure interaction using finite-element modelling in calculating scoured bridge natural frequencies. A full-scale field experiment was undertaken to validate the numerical model and it was concluded that frequency reduces with scour but the trend is non-linear due to nonuniform foundation sections and layered soils. It was also concluded that although the presence of fluid lowers the frequency value obtained, the fluid-structure effect is not obvious and therefore it may be neglected in the bridge natural frequency analysis.

\section{Development of Vehicle Bridge Soil Interaction (VBSI) model}

\section{Background}

This paper builds on work presented by Prendergast et al. (2013) in which a numerical soilstructure dynamic interaction model was developed to describe the change in natural frequency of a pile foundation subjected to scour. The model was shown to be capable of tracking the change in the natural frequency of a single pile affected by scour using input parameters which included the structural properties of the pile and the small strain stiffness of the soil. Experimental validation of the numerical model was undertaken both in a laboratory model scale and full-scale field test on a $8.76 \mathrm{~m}$ long pile embedded in dense sand. The pile geometry was typical of those used to support road and rail bridges. This validated numerical model is represented by the pile/spring system shown boxed in Fig. 1(a).

\section{Extended Model}

The work described by Prendergast et al. (2013) was validated for the case of a stand-alone pile foundation with forced vibration being imposed through the use of a modal hammer. In 
reality, pile foundations are used to provide vertical and/or lateral support for a structure (in this case a bridge) the presence of which will have a significant effect on the natural

121 frequency response of the pile-soil interaction problem. In this paper, the previously 122 developed model is extended to consider the effect of a bridge superstructure. The structure 123 considered is an integral bridge, comprised of two abutments, and a central pier supported on 124 pile foundations. The purpose of extending the model to include a bridge superstructure is to ascertain if it is possible to detect changes in the structure's natural frequency due to scour of the foundation and moreover to investigate if it is practicable to detect these changes by 127 analysing the acceleration signals caused by traffic loading (i.e. when a truck crosses the 128 bridge). Figs. 1(a) and (b) show a schematic of the un-scoured and scoured situations respectively. To make the simulated acceleration signals as realistic as possible, interaction effects between the vehicle and the bridge are considered and external noise is added to the signals. In this work, the change in natural frequency due to scour around the central pier

132 foundation is modelled, see Fig. 1(b). The possibility of detecting these changes by analysing 133 the acceleration response signals from vehicular loading is considered. Details of the model are given below. 


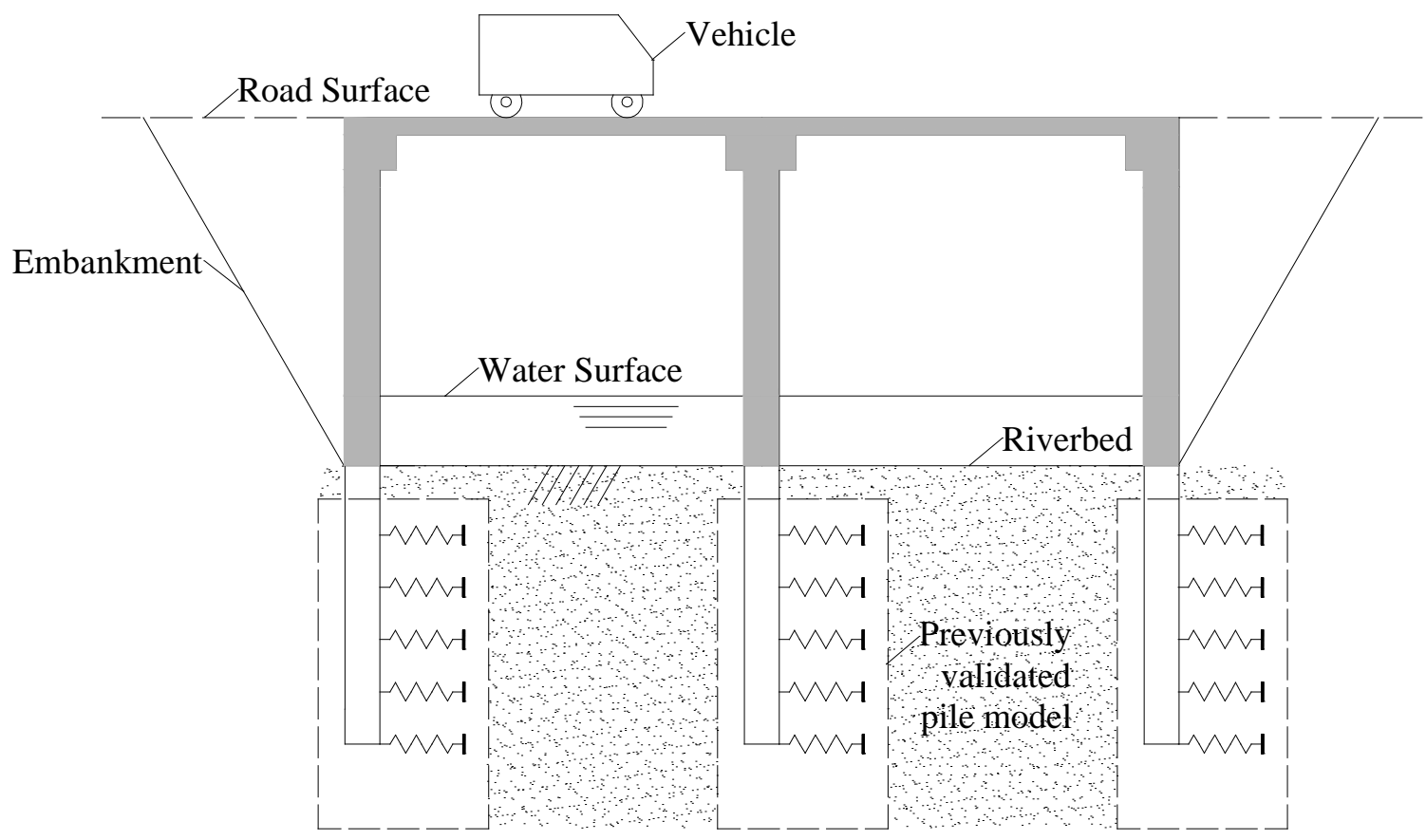

(a)

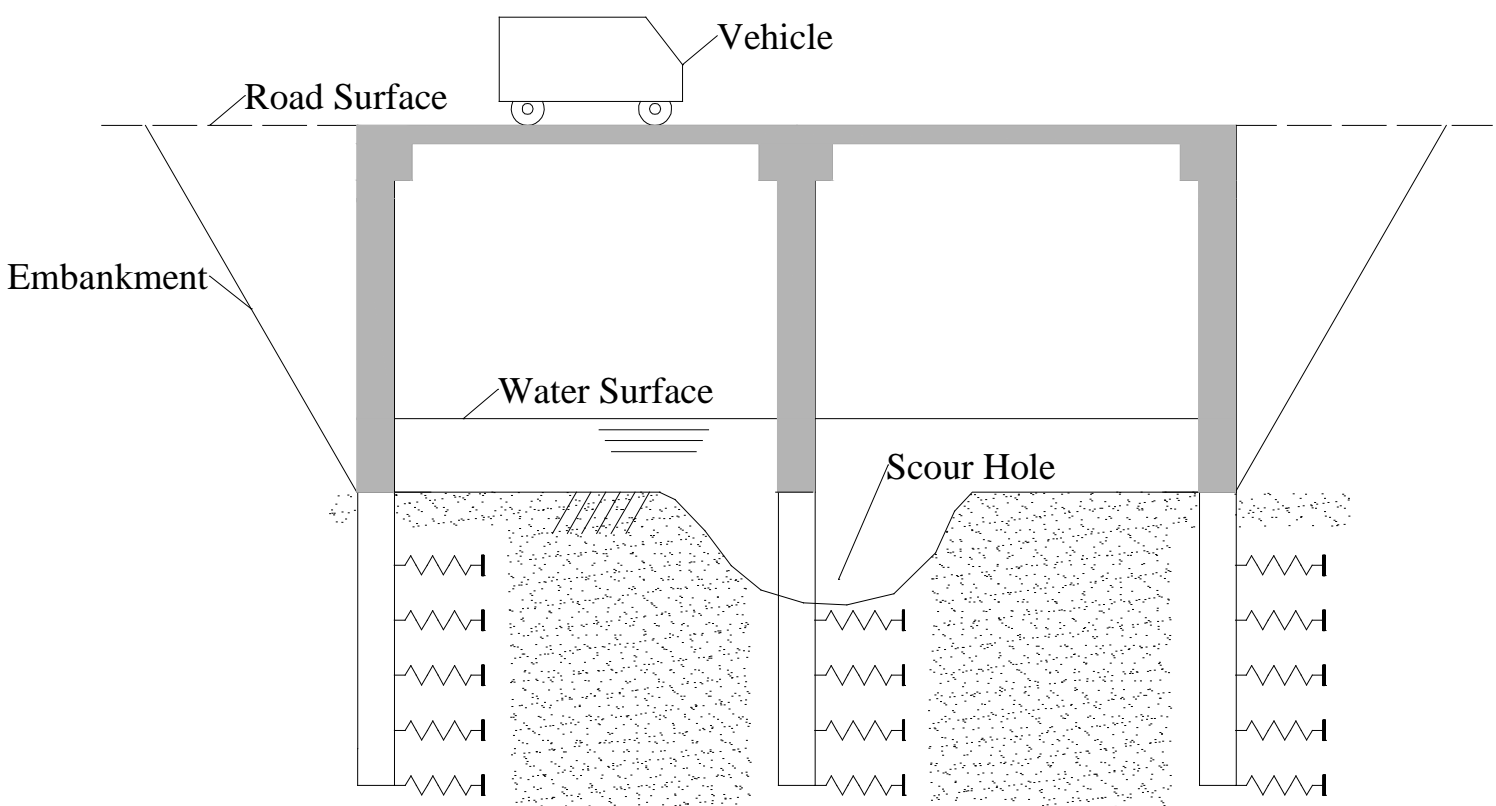

(b)

Fig. 1. Schematic of model. (a) un-scoured, (b) post scour. 


\section{Bridge structure to be modelled}

139 The bridge modelled is a two-span concrete integral bridge. A Young's modulus of $\mathrm{E}=$ $1403.5 \times 10^{10} \mathrm{~N} \mathrm{~m}^{-2}$ and a material density of $r=2400 \mathrm{~kg} \mathrm{~m}^{-3}$ are assumed for all bridge elements.

141 For this type of bridge the abutment is formed using a series of vertical concrete columns and 142 reinforced earth. The columns support the deck and the reinforced earth retains the 143 embankment fill, see Fig. 2. The bridge is not intended to represent any particular real-life structure. However, the properties were chosen to be representative of bridges of this type. The bridge deck is comprised of nine U10 concrete bridge beams (Concast 2014). Each beam supports a $200 \mathrm{~mm}$ deep deck slab giving a total combined moment of inertia of $\mathrm{I}=2.9487$ $\mathrm{m}^{4}$ and a cross-sectional area of $\mathrm{A}=9.516 \mathrm{~m}^{2}$ for the bridge deck, which are typical values for this type of bridge. The abutment consists of nine concrete columns supporting the bridge deck, each column is $500 \mathrm{~mm}$ in diameter and the columns are at $1900 \mathrm{~mm}$ centres, see Fig. 2(c). This results in a total moment of inertia of $\mathrm{I}=0.0276 \mathrm{~m}^{4}$ and a cross-sectional area of A $=1.7671 \mathrm{~m}^{2}$ for the abutment elements. This type of bridge does not have a conventional expansion joint so the thermal movements of the deck have to be accommodated by lateral movements of the abutment columns. To facilitate this movement, the abutment columns are cast in vertical sleeves so that there is a gap of 50 to $100 \mathrm{~mm}$ on all sides, i.e. the reinforced earth provides no lateral restraint to the columns. These abutment columns are therefore assumed free to move laterally. Two large concrete piers support the bridge at the centre and have plan dimensions of $1375 \mathrm{~mm}$ x $2625 \mathrm{~mm}$. This results in a total combined moment of inertia of $\mathrm{I}=1.137 \mathrm{~m}^{4}$ and a cross-sectional area of $\mathrm{A}=7.22 \mathrm{~m}^{2}$ for the combined bridge pier element. The piers are large stiff elements and they provide lateral restraint to the bridge deck.

The abutment columns each rest on a pilecap, under which ten $15 \mathrm{~m}$ long concrete bored piles are used as the foundation system, see Fig. 2. The pier columns each rest on a pilecap 
163 supported by four piles. The scour action is assumed to be uniform along the transverse 164 length of a given support, so for modelling purposes, the structure shown in Fig. 2 is idealised 165 as the 2D frame shown in Fig. 3. (Note: scour is assumed to be equal on both sides of the 166 pier). The properties of each of the elements of the model in Fig. 3 are calculated by 167 summing the properties of the individual components shown in Fig. 2. For example, the moment of inertia of the left abutment column shown in Fig. 3 is calculated by summing the moment of inertia of the nine abutment columns shown in Fig. 2. Similarly the stiffness of the two leaves of the pier shown in Section A-A of Fig. 2 is attributed to the central pier element

171 of Fig. 3. When apportioning stiffness to the pile elements shown in Fig. 3, a similar 172 philosophy was adopted. The abutment piles modelled have a combined cross-sectional area 173 of $\mathrm{A}=2.827 \mathrm{~m}^{2}$ and a moment of inertia of $\mathrm{I}=0.0636 \mathrm{~m}^{4}$ whereas the central pier piles have $174 \mathrm{~A}=3.534 \mathrm{~m}^{2}$ and $\mathrm{I}=0.1243 \mathrm{~m}^{4}$. Details on the spring stiffness coefficients used to model the 175 soil are given below and are summarised in Fig. 4. 


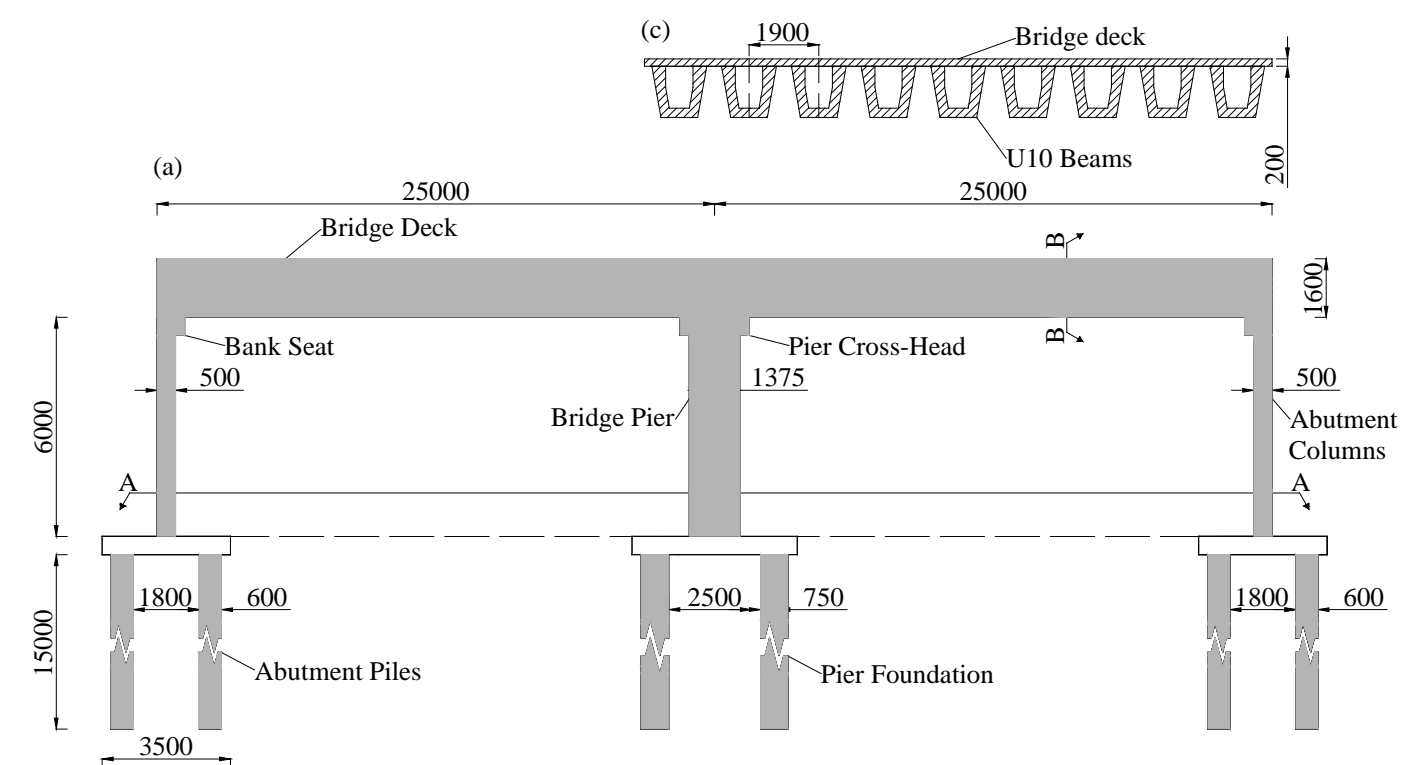

(b)
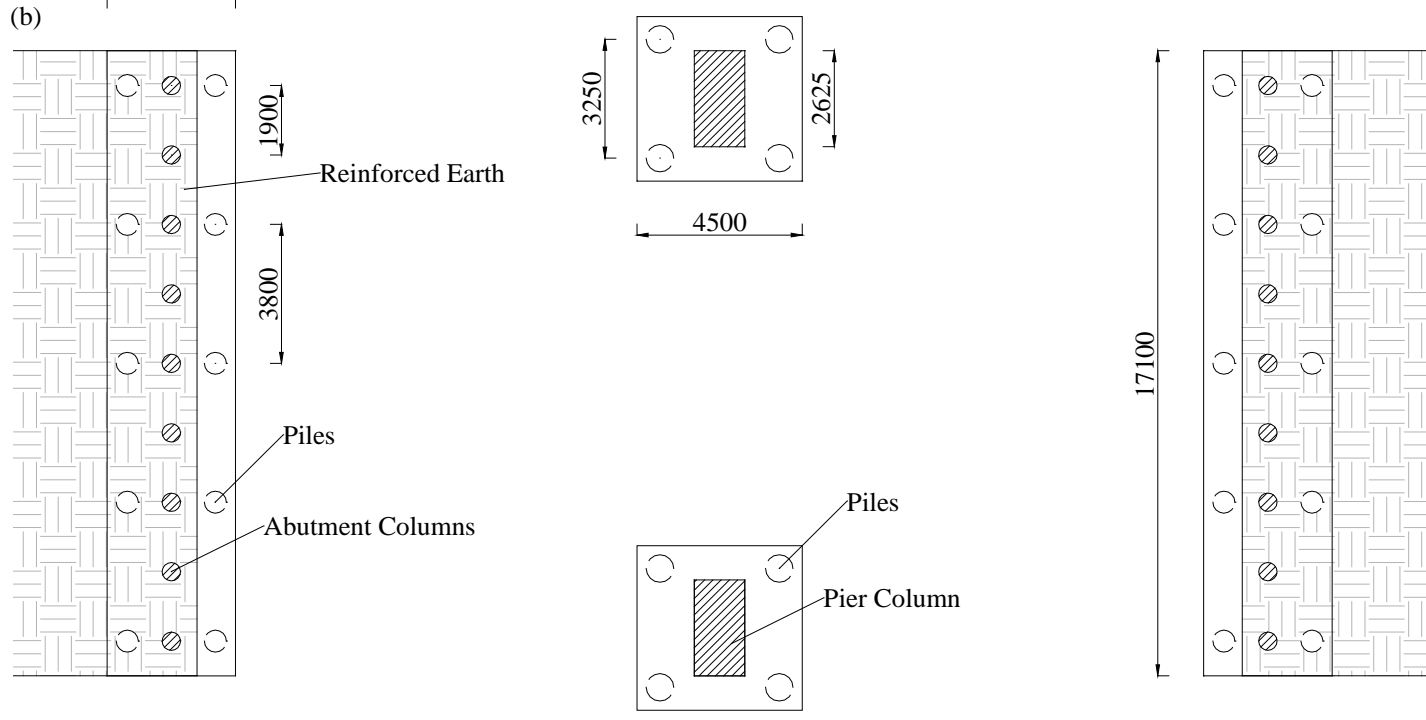

Fig. 2. Bridge layout with all dimensions shown in mm (a) elevation; (b) section A-A; (c)

\section{Numerical modelling approach}

181 The specific technical details of the model used in this paper have been published in 182 Prendergast et al. (2016b), therefore this section does not provide too much detail on the model. However an overview of the modelling approach is provided, in particular the

184 philosophy for modelling the bridge, the vehicle, and the soil is briefly discussed. The model is developed using MATLAB. 


\section{Bridge model}

188

The elements used in the bridge model are 6 degree-of-freedom (DOF) Euler-Bernoulli frame elements (Kwon and Bang 2000). Each frame element has two nodes and each node has an axial, transverse and a rotational degree of freedom as shown in the insert in Fig. 3.

The global mass and stiffness matrices for the model are assembled together according to the procedure outlined in Kwon and Bang (2000). Damping is modelled using a Rayleigh damping approach, with a damping ratio of $2 \%$ being assumed for all simulations in this paper. The dynamic response of the bridge is obtained by solving the second order matrix differential equation shown in Eq. (1).

$$
\mathbf{M} \ddot{\mathbf{x}}(t)+\mathbf{C} \dot{\mathbf{x}}(t)+\mathbf{K x}(t)=\mathbf{F}(t)
$$

where $\mathbf{M}, \mathbf{C}$ and $\mathbf{K}$ are the $(n D O F \times n D O F)$ global consistent mass, damping and stiffness matrices respectively, and $n D O F$ is the total number of degrees of freedom in the system. The vector $\mathbf{x}(t)$ describes the displacement of every degree of freedom for a given time step in the analysis. Similarly, the vectors $\dot{\mathbf{x}}(t)$ and $\ddot{\mathbf{x}}(t)$ describe the velocity and acceleration of every degree of freedom in the model for the same time step. The vector $\mathbf{F}(t)$ describes the external forces acting on each degree of freedom for a given time step in the analysis. Eq. (1) is solved using a numerical integration scheme, the Wilson-theta method (Dukkipati 2009).

Mode shapes and natural frequencies were extracted from the model by performing an eigenvalue analysis on the system. In order to verify that the model was operating correctly, the static displacements, mode shapes and natural frequencies predicted by the model were verified against those calculated by a commercially available finite-element package. Good agreement was observed between the model and the commercial software. 
211 The vehicle model, used in this work is similar to the model described in Hester and

212 González (2012) and González and Hester (2013). The vehicle model has four degrees of

213 freedom, namely a vertical displacement for each of the two axles ( $\mathrm{y}_{1}$ and $\mathrm{y}_{2}$ ), the body

214 bounce $\left(\mathrm{y}_{\mathrm{b}}\right)$ and body pitch $\left(\varphi_{\mathrm{p}}\right)$, see Fig. 3 . The body has mass $\mathrm{m}_{\mathrm{b}}$ and has rotational moment

215 of inertia $I_{p}$ (for pitch). The body is supported on a suspension/axle assembly. The mass of

216 the wheel/axle assembly is $m_{w}$. The suspension has a stiffness $K_{s}$ and a damping coefficient

217 Cs. Finally, the tyre is modelled as a spring with stiffness $\mathrm{K}_{\mathrm{t}}$. Table 1 provides the parameters

218 of the vehicle (Cantero et al. 2011; El Madany 1988). Using the properties given in Table 1,

219 stiffness $\mathbf{K}_{\mathbf{v}}$, mass $\mathbf{M}_{\mathbf{v}}$ and damping $\mathbf{C}_{\mathbf{v}}$ matrices for the vehicle can be populated. The natural

220 frequencies of the vehicle for bounce, pitch, and front and rear axle hops are $1.43 \mathrm{~Hz}, 2.07$

$\mathrm{Hz}, 8.860 \mathrm{~Hz}$ and $10.22 \mathrm{~Hz}$ respectively.

Table 1. Parameters of vehicle model.

\begin{tabular}{lll}
\hline Parameter & Property & Value \\
\hline \multirow{2}{*}{ Dimensions $(\mathrm{m})$} & Wheel base $(\mathrm{S})$ & 5.5 \\
& Dist from centre of mass to front axle $\left(\mathrm{S}_{1}\right)$ & 3.66 \\
& Dist from centre of mass to rear axle $\left(\mathrm{S}_{2}\right)$ & 1.84 \\
\hline \multirow{2}{*}{ Mass $(\mathrm{kg})$} & Front wheel/axle mass $\left(\mathrm{m}_{\mathrm{w} 1}\right)$ & 700 \\
& Rear wheel/axle mass $\left(\mathrm{m}_{\mathrm{w} 2}\right)$ & 1,100 \\
& Sprung body mass $\left(\mathrm{m}_{\mathrm{b}}\right)$ & 13,300 \\
Inertia $\left(\mathrm{kg} \mathrm{m}^{2}\right)$ & Pitch moment of inertia of truck $\left(\mathrm{I}_{\mathrm{p}}\right)$ & 41,008 \\
\hline \multirow{2}{*}{ Spring stiffness $\left(\mathrm{kN} \mathrm{m}^{-1}\right)$} & Front axle $\left(\mathrm{K}_{\mathrm{s} 1}\right)$ & 400 \\
& Rear axle $\left(\mathrm{K}_{\mathrm{s} 2}\right)$ & 1,000 \\
Damping $\left(\mathrm{kN} \mathrm{s} \mathrm{m}^{-1}\right)$ & Front axle $\left(\mathrm{C}_{\mathrm{s} 1}\right)$ & 10 \\
& Rear axle $\left(\mathrm{C}_{\mathrm{s} 2}\right)$ & 10 \\
Tyre stiffness $\left(\mathrm{kN} \mathrm{m}^{-1}\right)$ & Front axle $\left(\mathrm{K}_{\mathrm{t} 1}\right)$ & 1,750 \\
& Rear axle $\left(\mathrm{K}_{\mathrm{t} 2}\right)$ & 3,500 \\
\hline
\end{tabular}


Modelling the dynamic behaviour of a vehicle-bridge interaction system is complex as there are two sub-systems, namely the moving vehicle and the bridge/substructure. These two systems interact with each other via the contact forces that exist between the vehicle wheels and the bridge surface, therefore mathematically the problem is coupled and time dependant (Yang et al. 2004). It is necessary to solve both subsystems while ensuring compatibility at the contact points (González 2010). In this paper, an iterative approach was employed to implement the VBI model (Green and Cebon 1997; Yang and Fonder 1996), see Prendergast et al. (2016b) for more information.

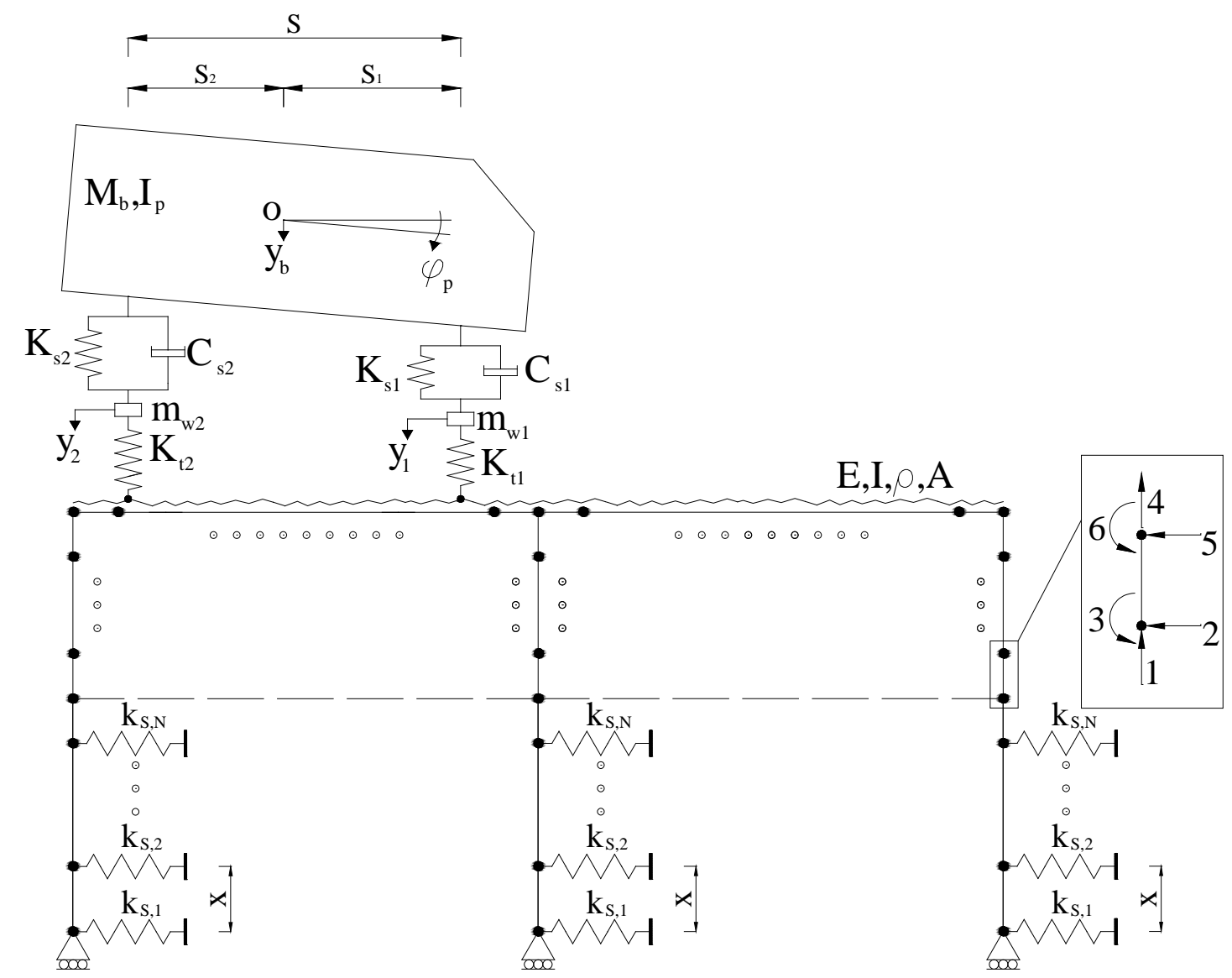

Fig. 3. Schematic of the Vehicle-Bridge-Soil Interaction (VBSI) model.

Calculating soil spring stiffness

237 Soil-structure interaction is incorporated into the model by means of the Winkler method. The soil is modelled as a system of discrete, mutually independent and closely-spaced lateral 
springs (Dutta and Roy 2002; Winkler 1867). The method for developing spring stiffness values is based on Prendergast et al. (2013) who derived spring stiffness values using the small-strain shear modulus $\left(\mathrm{G}_{0}\right)$ profile from their experimental site. Full details on calculating soil spring stiffness coefficients is available in Prendergast and Gavin (2016a) and Prendergast et al. (2015). The spring stiffness profiles used in this paper are shown in Fig. 4 for loose, medium-dense and dense sand. The individual spring stiffness moduli are shown by the data markers on the plot. These profiles are for the central pier foundation piles.

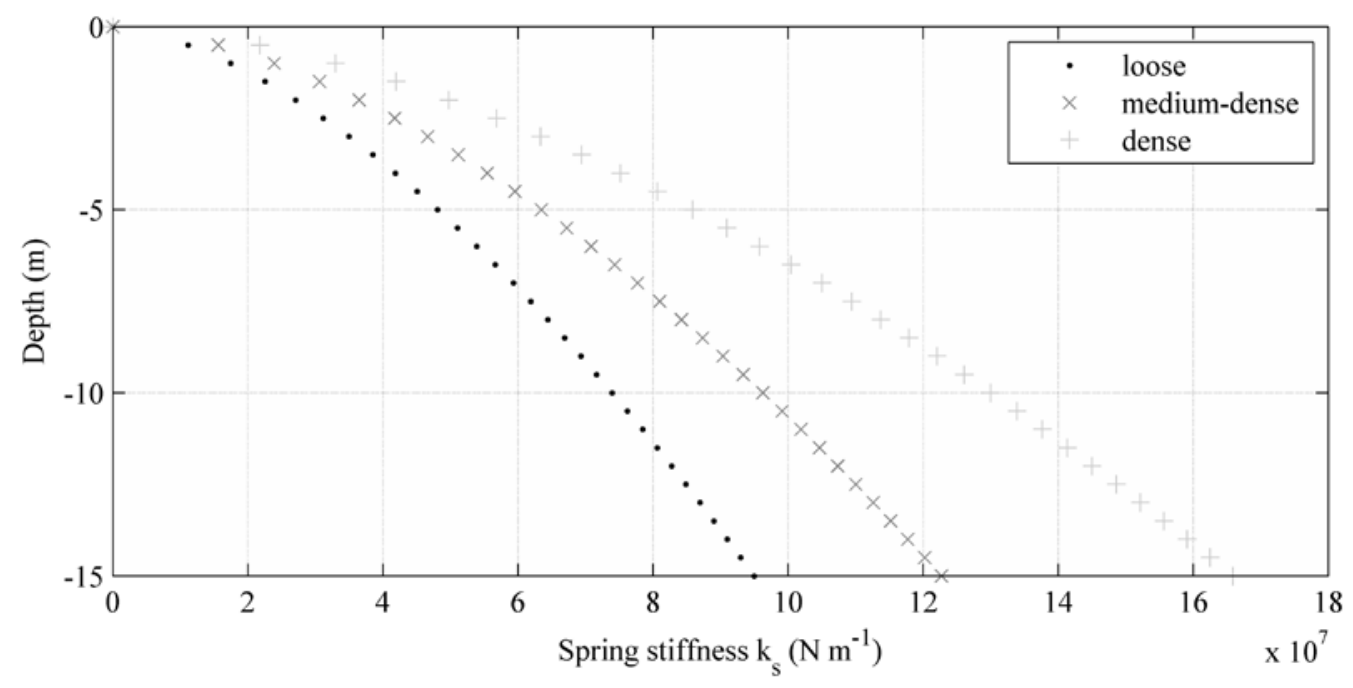

Fig. 4. Postulated soil spring stiffness profiles for a loose, medium-dense and dense sand around the central pier piles $\left(\mathrm{N} \mathrm{m}^{-1}\right)$ for the analysis.

\section{Analysis \& results}

In the analyses performed using the model described previously, a moving vehicle excites the bridge. The lateral response of the bridge is excited by the vehicle moving over the bridge, inducing moments at the head of the abutments and the pier causing lateral sway. Horizontal vehicle forces that would be induced by vehicle acceleration and braking are not included in the model. However, these may contribute to the lateral response on a real system. The vehicle crosses the bridge at typical highway speed and the horizontal acceleration from the 
top of the pier is recorded and analysed. The effect of (initial) soil stiffness on the frequency changes with scour was examined for the three soil stiffness profiles. To aid in choosing appropriate locations to place accelerometers on the structure and to ascertain a baseline for the expected change in natural frequency due to scour, an eigenvalue modal analysis was conducted in the first instance.

\section{Eigen frequencies and mode shapes}

An eigenvalue analysis was conducted in the model to extract the fundamental frequency of (lateral) vibration for different depths of scour. A maximum scour depth of $10 \mathrm{~m}$ was considered in the model and the difference in frequency between zero scour and this maximum value is shown in Table 2. The results indicate that a scour depth of $10 \mathrm{~m}$ produced a change in fundamental frequency of $\approx 40 \%$ for the three soil stiffness profiles considered.

Once the expected shift in frequency due to scour was established, the next step was to determine the optimum points on the structure to record accelerations to give the best opportunity to capture the first mode of vibration of the integral bridge. By plotting the first mode shape of the structure for zero scour and full pier scour, it is possible to obtain a pictorial view of the locations showing the highest modal displacements for the fundamental mode. Fig. 5 shows that the first mode shape for both zero scour and maximum pier scour (10 $\mathrm{m})$ is a global sway mode. The data shown in Fig. 5 was for the analysis performed in loose sand. However, the shape was the same for all three soil stiffness profiles considered. From the figure, it can be seen that the maximum modal amplitude occurs at deck level. In this study the top of the bridge pier is used as the location to measure acceleration as it assists in identifying the frequency when using signal processing and also aids with signal to noise ratio (SNR) issues. 
Table 2. Eigenvalue analysis of the scour effect.

\begin{tabular}{lccc}
\hline \multicolumn{1}{c}{ Scour depth $(\mathrm{m})$} & $\begin{array}{c}\text { Frequency (loose } \\
\text { sand) }(\mathrm{Hz})\end{array}$ & $\begin{array}{c}\text { Frequency (medium } \\
\text { dense sand) }(\mathrm{Hz})\end{array}$ & $\begin{array}{c}\text { Frequency (dense } \\
\text { sand) }(\mathrm{Hz})\end{array}$ \\
\hline $0 \mathrm{~m}$ & 1.5643 & 1.6481 & 1.7357 \\
$10 \mathrm{~m}$ (full) & 0.9386 & 0.9772 & 1.017 \\
$\%$ Difference & $-39.99 \%$ & $-40.708 \%$ & $-41.4 \%$ \\
\hline
\end{tabular}

(a)

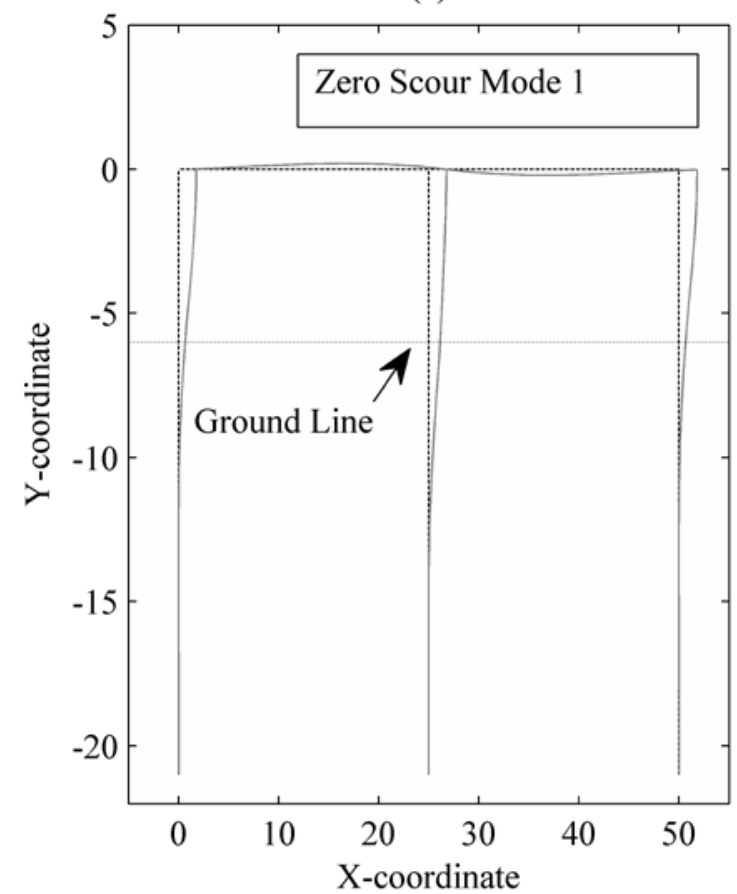

(b)

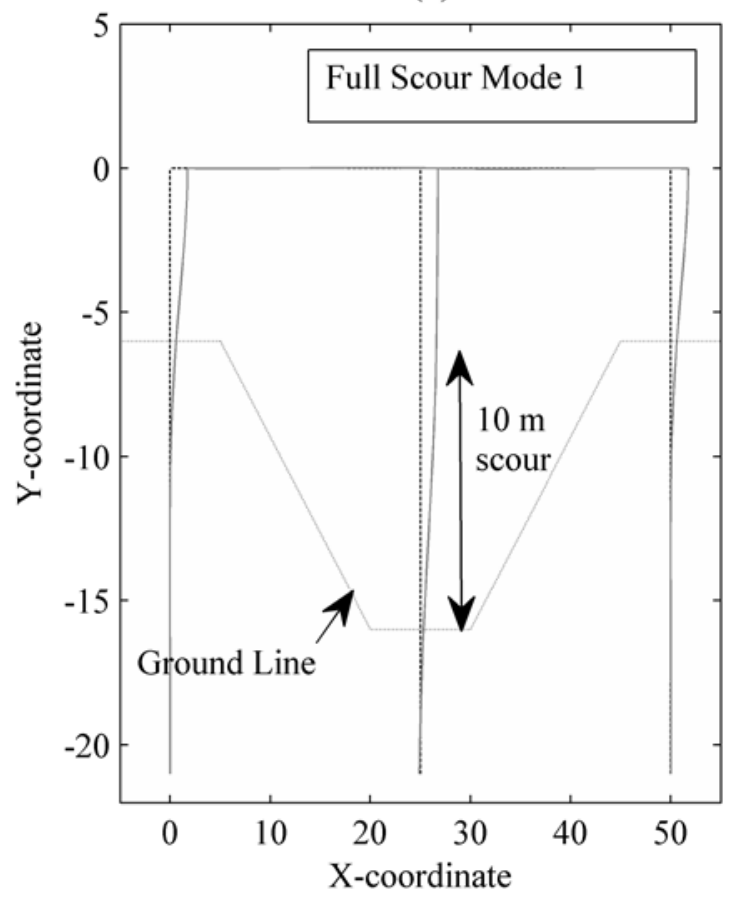

283

Fig. 5. Fundamental mode shapes in loose sand - global sway. (a) zero scour (b) full scour.

\section{Response of structure to moving half-car vehicle model}

\section{Simulation of noise free pier accelerations due to the passage of a vehicle}

From the eigenvalue analysis in the previous section, it was observed that significant reductions in natural frequency occurred due to scour of the central pile foundation system. However, the fact that frequency changes will occur is of little use if the relevant mode is not excited in the structure. The most practical way to excite a rail / highway bridge is to use ambient traffic (Farrar et al. 1999). Therefore in this section the aim is to ascertain if it is possible to detect these frequency changes by analysing the bridge acceleration response to a 
moving sprung vehicle. In this analysis, accelerations generated at a lateral degree of freedom near the top of the bridge pier are analysed using a fast Fourier transform to obtain the frequency content. The vehicle modelled is a 15 tonne two-axle truck (see Table 1), and to make the model as realistic as possible interaction between the vehicle and the bridge is allowed for. The bridge is excited by the sudden arrival of the vehicle on the bridge deck, which effectively acts as an impulse load.

The vehicle is a four-degree-of-freedom system that moves along the bridge deck. The vehicle is excited by the presence of a road profile which causes the body to pitch and bounce and this in turn means that the forces that the vehicle applies to the bridge are not constant. In the model the vehicle commences movement at an approach distance of $100 \mathrm{~m}$ from the start of the bridge so that the initial vehicle motion conditions (axle displacements and body displacement / pitch) when the vehicle meets the bridge are more realistic. The road profile used in the current analysis is a Class ' $A$ ' profile (well-maintained road surface, see Cebon (1999)), and the part of the road profile on the bridge is reproduced in Fig. 6. This figure also shows a Class ' $\mathrm{B}$ ' and a Class 'C' road profile, in order of degrading quality.

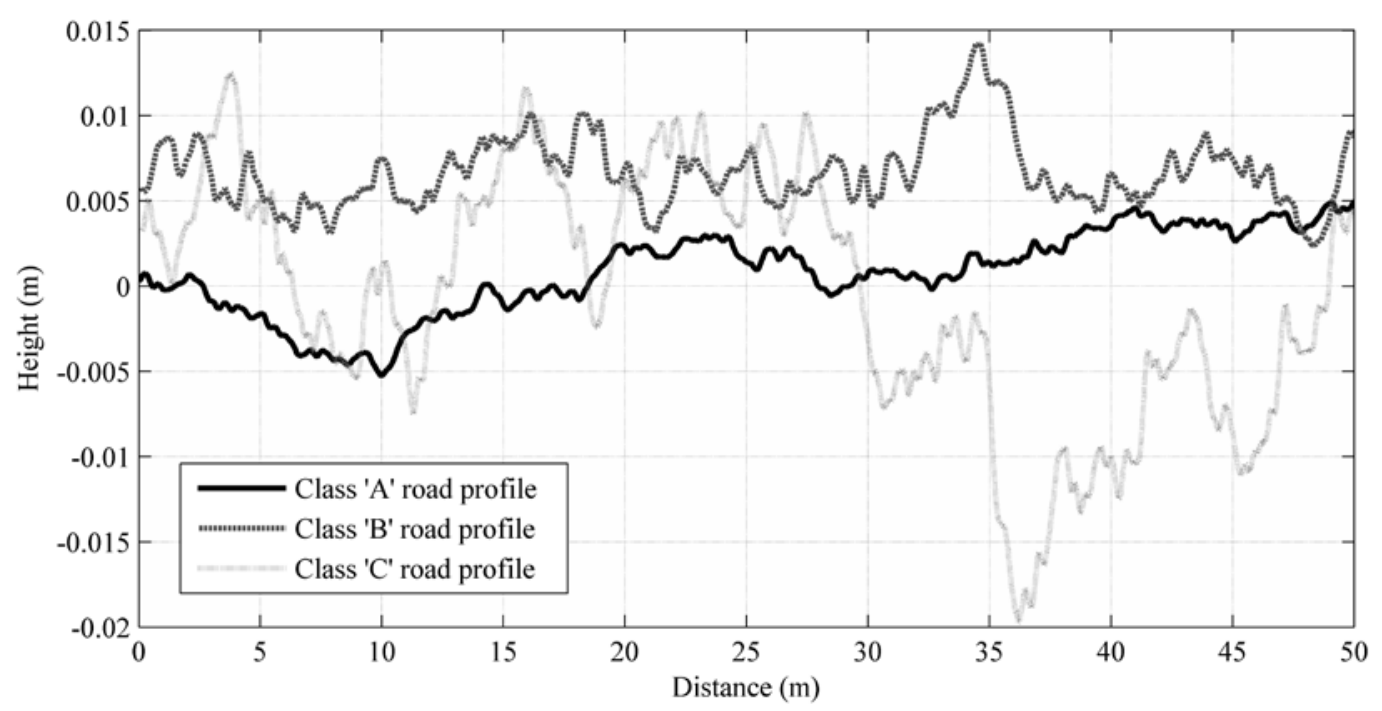

Fig. 6. Road profiles on the bridge. 
312 The vertical forces generated by the vehicle moving over the Class ' $A$ ' road profile are 313 shown in Fig. 7(a) for a vehicle speed of $80 \mathrm{~km} \mathrm{hr}^{-1}$, the loose sand soil profile and the case of 314 zero scour. In Fig. 7(a) it can be seen that the rear axle is significantly heavier than the front 315 axle and this is typical of a fully loaded 2 axle truck.

316 Fig. 7(b) shows the lateral acceleration response of the top of the pier when the truck crosses 317 the bridge (for the loose sand profile). The large peaks in acceleration at 0 seconds and 2.5 seconds correspond to the vehicle entering and leaving the bridge. After the vehicle leaves the bridge there is a logarithmic decay in the acceleration signal over the following 27.5 seconds. This is to be expected as a damping ratio of $2 \%$ is used in the simulations.

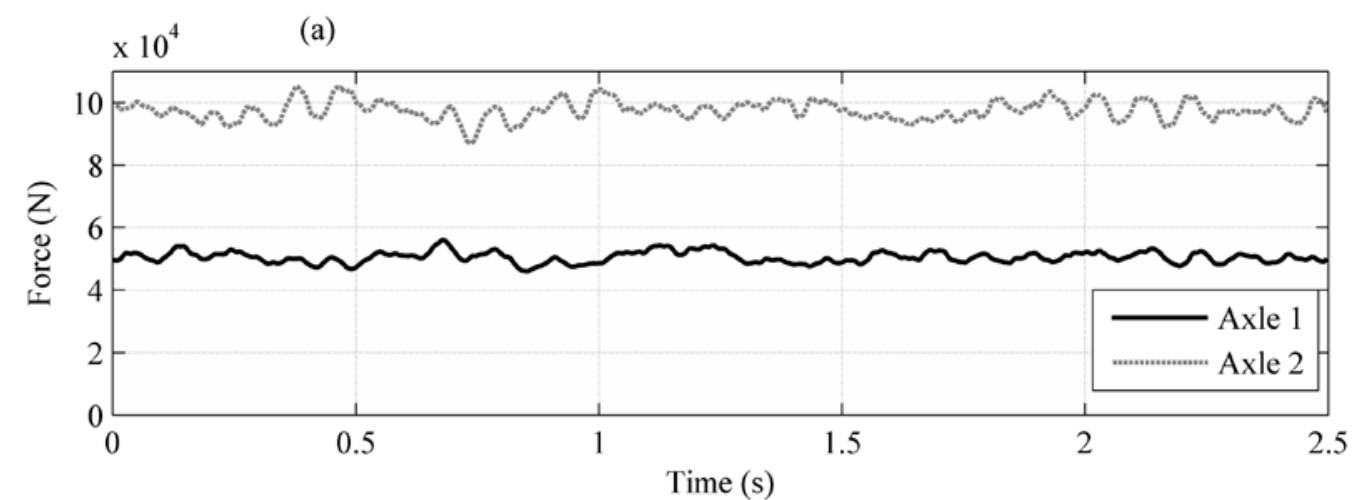

(b)

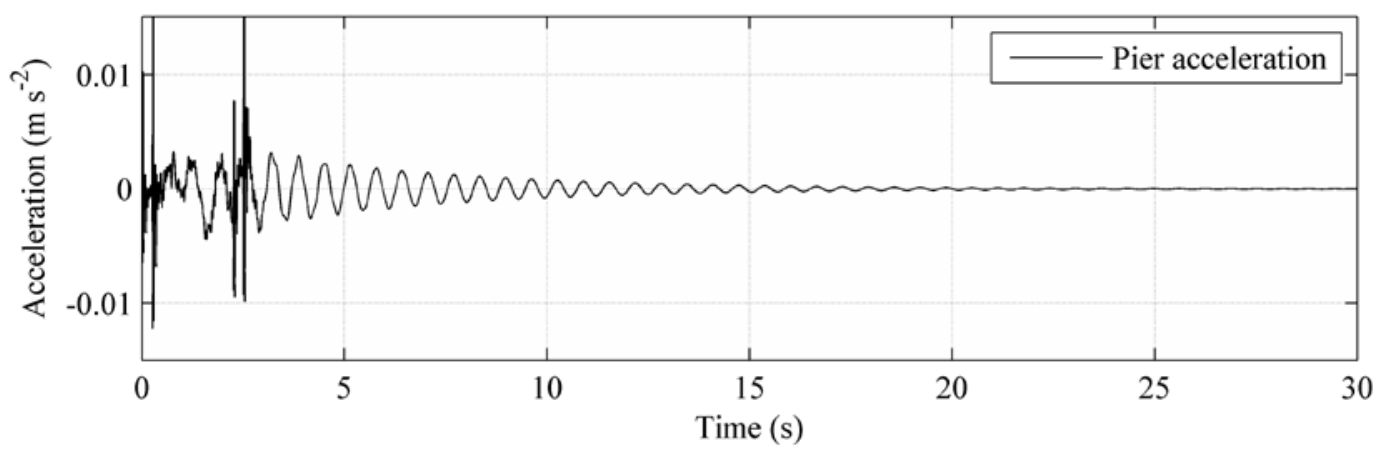

321

Fig. 7. Results for vehicle crossing bridge for zero scour level and loose sand profile (a) axle contact forces (b) lateral acceleration response at top of pier. 
327 Real data will contain noise, so in this study, noise was added to the simulated signal. In order to check if the (scour detection) method was sensitive to the level of noise in the signal, signals with different levels of noise are analysed. The method used to add noise is based on the signal-to-noise ratio (SNR), given in Eq. (2) (Lyons 2011).

$$
S N R=10 \log _{10} \frac{\text { Signal Power }}{\text { Noise Power }}
$$

where SNR is the ratio of the strength of a signal carrying information equating to that of unwanted interference. Eq. (2) is rearranged to give Eq. (3).

$$
\sigma_{\mathrm{N}}=\sqrt{\text { Noise Power }}=\sqrt{\frac{\text { Signal Power }}{\exp \left(\frac{\text { SNR. } \log _{\mathrm{e}}(10)}{10}\right)}}
$$

where $\sigma_{\mathrm{N}}$ is the noise variance. Using Eq. (3), noise signals with different signal-to-noise ratios were added to the original clean signal. This process is shown in Eq. (4).

$$
\operatorname{Sig}_{\text {NOISE }}=\sigma_{N}[\text { rand }]+\operatorname{Sig}_{\text {CLEAN }}
$$

In this study, three noise levels were examined, namely SNRs of 20, 10 and 5. Figs. 8(a-c) show the result of adding noise to the signal shown in Fig. 7(b). Fig. 8(d) shows the frequency content of the signals in Fig. 8(a-c). It can be seen in the figure that for all levels of noise the frequency plot is practically identical which proves that the method will not be particularly sensitive to noise. For the purpose of completeness, the figure has an insert which shows a zoomed in view of the frequency peak. In the insert it can be seen that that there are small differences in the frequency peak for the different levels of noise. However, in relative terms these differences are insignificant. Since noise does not impede the ability of the method to detect the frequency accurately, all analysis from this point will contain a SNR = 20 as it is easier for the reader to interpret the remaining time domain plots for lower values of noise. 
(a)

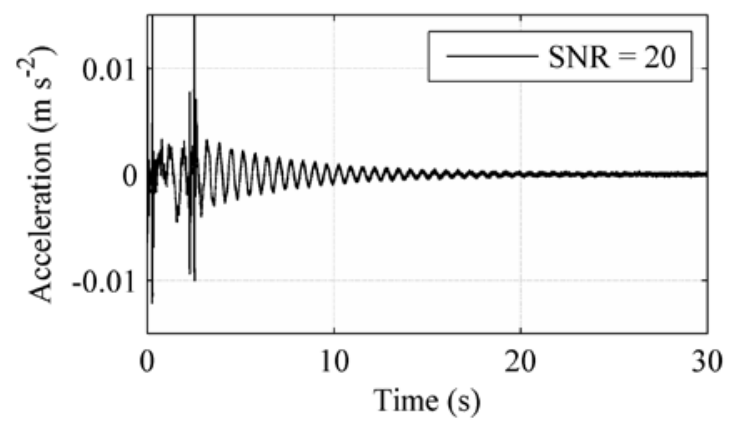

(c)

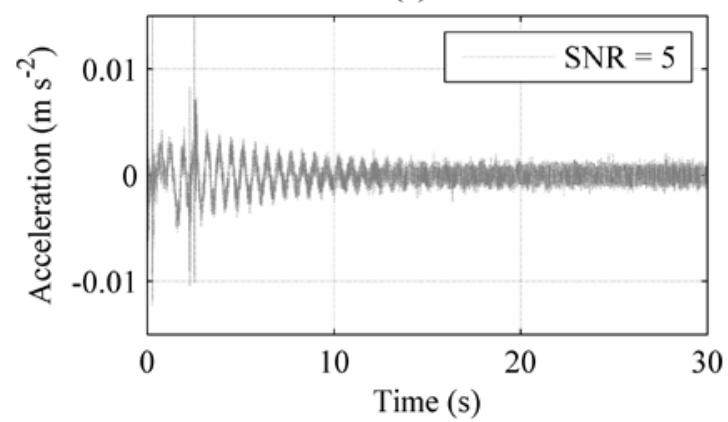

(b)

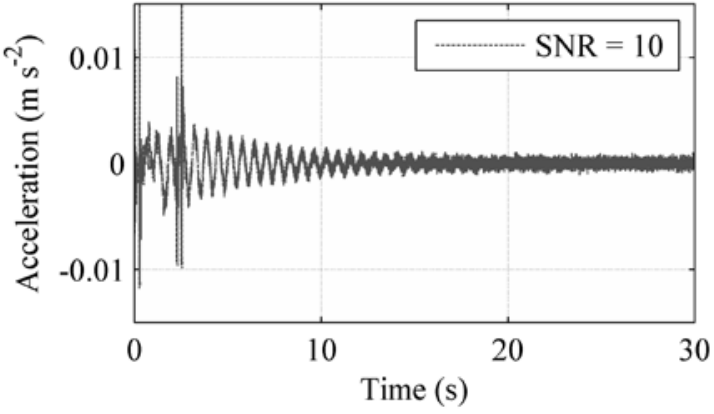

(d)

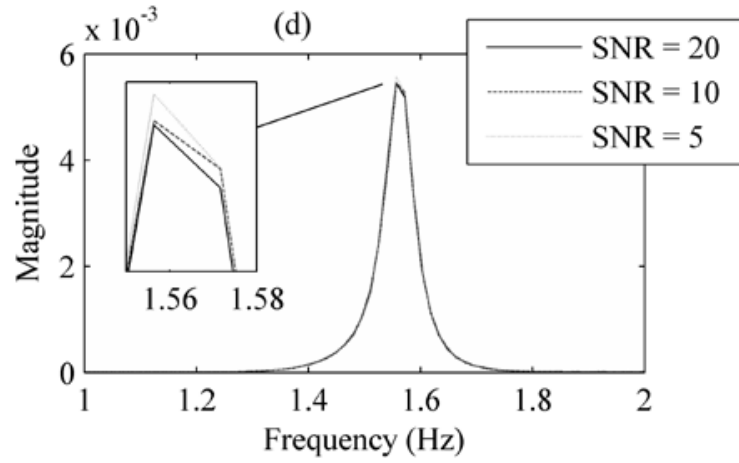

Fig. 8. Sensitivity of frequency content to noise. (a) signal from bridge pier with SNR = 20,

(b) signal with SNR = 10, (c) signal with SNR $=5$, (d) frequency content of signals shown in

Effect of vehicle properties, driving speed and road profile on detecting the frequency of the pier vibrations

In the previous section, it was established that artificially added noise does not significantly impede the method of detecting the first natural frequency of the structure (global sway) from the pier accelerations due to a passing vehicle. However, the analysis in the previous section only considers one set of vehicle properties, one driving speed and a Class 'A' road profile. In this section, the effect of varying the driving speed, vehicle properties and road roughness condition on the resilience of the method is investigated. Fig. 9 shows the effect of varying

362 the vehicle driving speed on the detected first natural frequency of the bridge. In this figure, the vehicle traverses the bridge at 50, 80 and $100 \mathrm{~km} \mathrm{hr}^{-1}$ and the lateral acceleration signal 
generated at the pier head is analysed for its frequency content. The vehicle traverses a Class ' $A$ ' road profile and the soil is assumed as loose sand with zero scour affecting the structure. Fig. 9(a) shows the lateral acceleration of the pier head generated due to a vehicle passing at $50 \mathrm{~km} \mathrm{hr}^{-1}$. Similarly, Figs. 9(b) and (c) show the lateral acceleration of the pier head 368 generated due to a vehicle passing at $80 \mathrm{~km} \mathrm{hr}^{-1}$ and $100 \mathrm{~km} \mathrm{hr}^{-1}$ respectively. All signals contain a SNR $=20$. Fig. 9(d) shows the frequency content of the signals in Figs. 9(a-c). As is evident, the frequency of the three signals is broadly in agreement (with minute differences

371 arising due to frequency resolution issues due to different signal lengths). The magnitude of 372 the frequency response differs between the three signals. This is as a result of interaction 373 effects between the vehicle travelling speed and the bridge's own dynamic motion. In short, 374 the rate at which the vehicle traverses the two-span bridge can either magnify or diminish the 375 bridge response depending on where the vehicle is on the bridge relative to the oscillation cycle of the bridge itself, more information on this phenomenon is available in Prendergast et al. (2016b). Overall, the frequency detection method is not particularly sensitive to vehicle 378 travelling velocity; therefore all further analyses in this paper are undertaken for a highway speed of $80 \mathrm{~km} \mathrm{hr}^{-1}$. 
(a)

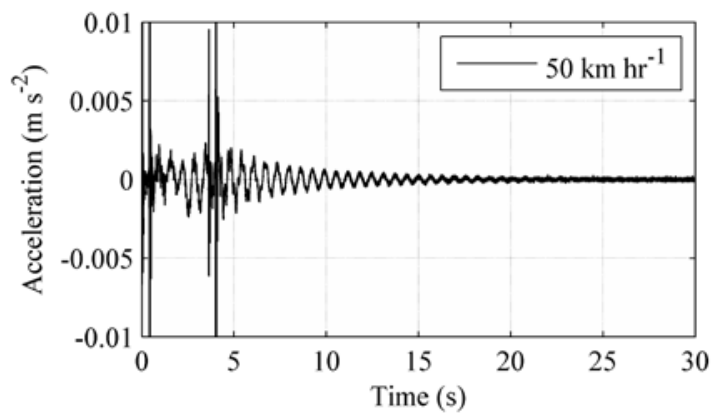

(c)

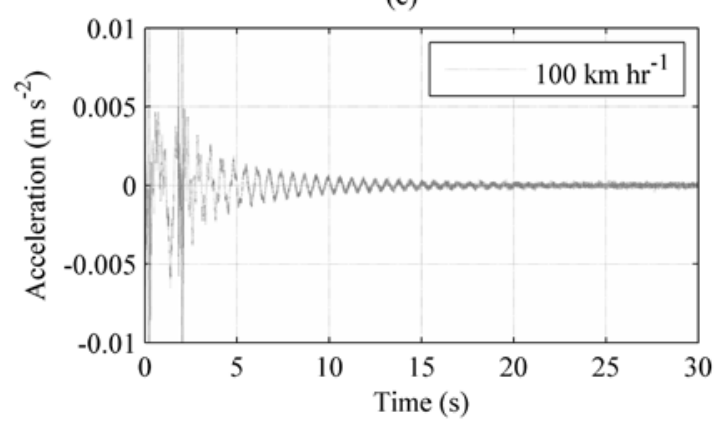

(b)

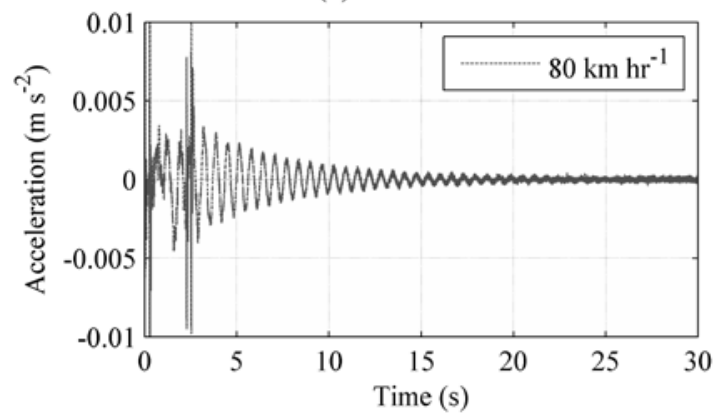

(d)

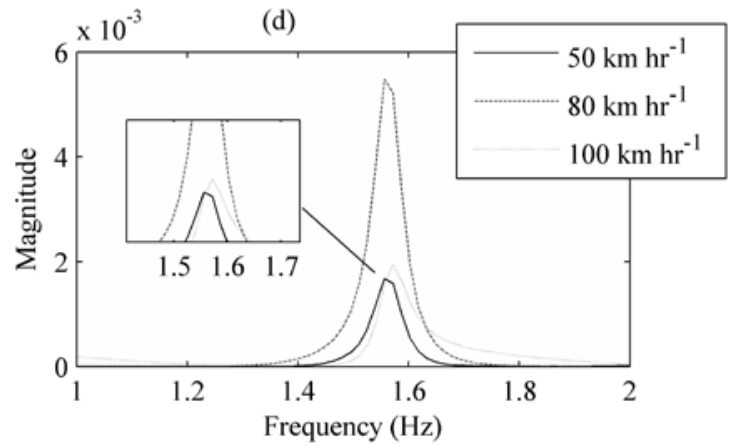

Fig. 9. Sensitivity of frequency content to vehicle speed. (a) signal from bridge pier with

382

vehicle speed $=50 \mathrm{~km} \mathrm{hr}^{-1}$, (b) signal with vehicle speed $=80 \mathrm{~km} \mathrm{hr}^{-1}$, (c) signal with vehicle

$$
\text { speed }=100 \mathrm{~km} \mathrm{hr}^{-1} \text {, (d) frequency content of signals shown in Figs. 9(a)-(c). }
$$

The vehicle modelled in the simulations undertaken previously is a two axle truck, the properties of which are shown in Table 1. In order to assess if the vehicle properties have any noticeable effect on the ability of the method to detect the bridge's first frequency from vehicle induced lateral motion, a brief analysis is conducted herein. For this analysis, the vehicle whose properties are outlined in Table 1 (Veh 1) is run across the bridge and compared to a modified vehicle (Veh 2), which includes an altered front axle stiffness and gross body mass. The relevant properties of both vehicles are outlined in Table 3 . 
Table 3. Veh 1 and Veh 2 properties for sensitivity analysis.

\begin{tabular}{lcc}
\hline & Veh 1 & Veh 2 \\
\hline Gross body mass (kg) & 13,300 & 9,000 \\
Front axle stiffness (kN m $\left.\mathbf{~}^{-\mathbf{1}}\right)$ & 400 & 600 \\
Body bounce frequency (Hz) & 1.43 & 1.84 \\
\hline
\end{tabular}

396

The result of running both vehicles over the bridge is shown in Fig. 10. Both vehicles traverse at $80 \mathrm{~km} \mathrm{hr}^{-1}$ over a bridge with zero scour, a loose sand profile and a Class 'A' road surface. Signals contain a SNR $=20$. Fig. 10 (a) shows the lateral pier head acceleration due to the passage of the original vehicle (Veh 1). Fig. 10(b) shows the lateral pier head acceleration due to the passage of the modified vehicle (Veh 2). Fig. 10(c) shows the frequency content of the signals in (a) and (b). As is evident, altering the vehicle properties does not significantly affect the frequency detection method, as the frequency is identical with only a minor change in magnitude. The analysis conducted here only considers a two-axle truck, however, so the effect for other vehicle types is not considered.

(a)

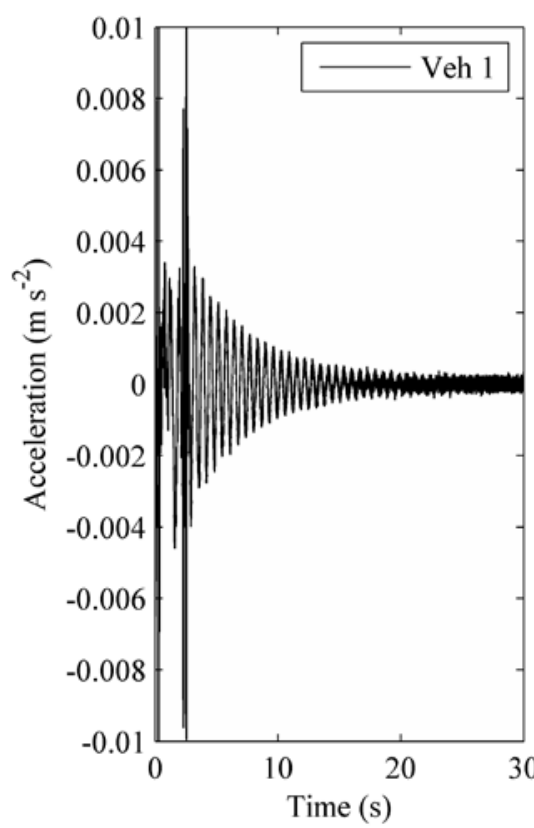

(b)

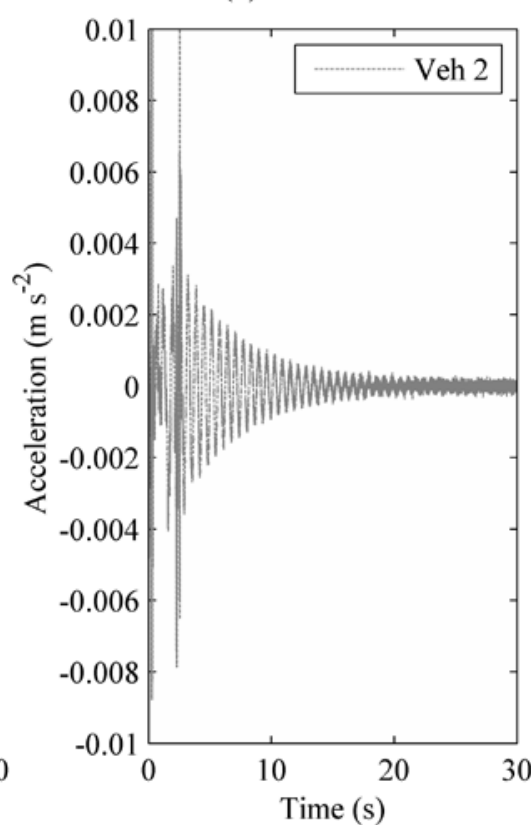

(c)

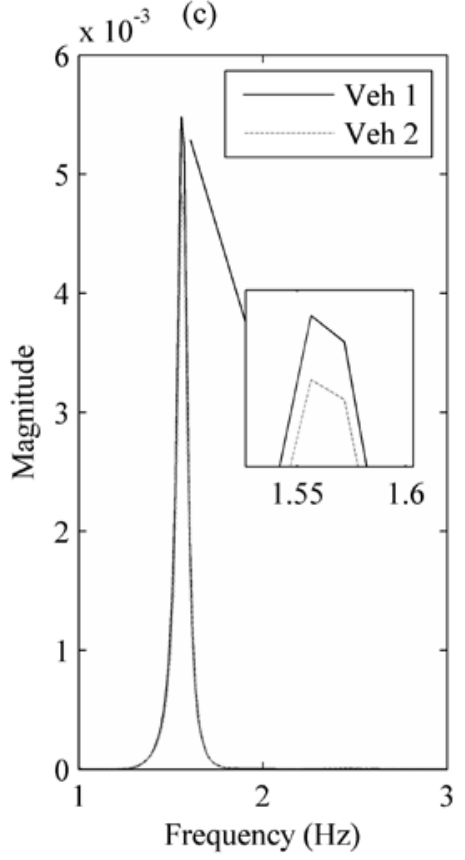

406

407

Fig. 10. Sensitivity of frequency content to vehicle mass and axle stiffness. (a) signal from bridge pier with original vehicle properties, (b) signal with modified vehicle properties (c) frequency content of signals shown in Figs. 10(a) and (b). 
411 Finally, it is of interest to assess if a degrading road surface will impede the ability for the

412 first natural sway frequency of the bridge to be detected from vehicle induced vibrations. For

413 this analysis, the original vehicle (Veh 1) traverses the bridge over a Class ' $A$ ', ' $B$ ' and ' $C$ '

414 profile at $80 \mathrm{~km} \mathrm{hr}^{-1}$ for the case of zero scour (see Fig. 6 for road profiles). All signals

415 contain a SNR $=20$. The results are shown in Fig. 11. Fig. 11(a) shows the lateral pier head

416 acceleration due to the vehicle traversing a Class 'A' road profile. Similarly, Figs. 11(b) and

417 (c) show the lateral pier head accelerations measured due to a vehicle traversing Class ' $\mathrm{B}$ '

418 and ' $C$ ' profiles respectively. Fig. 11(d) shows the frequency content of the signals presented

419 in parts (a) to (c) of the figure. The frequency peak corresponding to the first natural

420 frequency of the bridge is clearly detected in all three signals, with differences in magnitude

421 occurring for each road roughness profile. From this figure, it is clear that the presence of a

422 road roughness profile up to Class ' $\mathrm{C}$ ' does not significantly impede the ability for the bridge

423 frequency peak to be detected (only very minor differences in frequency are detected due to

424 resolution of frequency bins). As a result, all analyses from here will utilise a Class ' $A$ '

425 profile, equivalent to a well-maintained highway surface. In the next section, the detection of

426 scour from pier head lateral accelerations is investigated. 
(a)

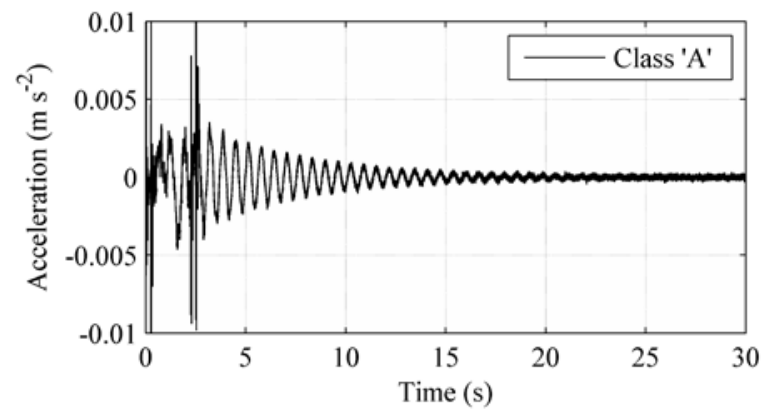

(c)

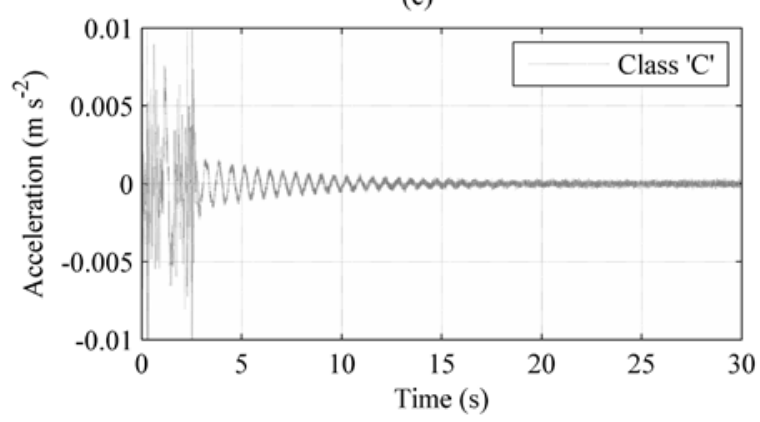

(b)

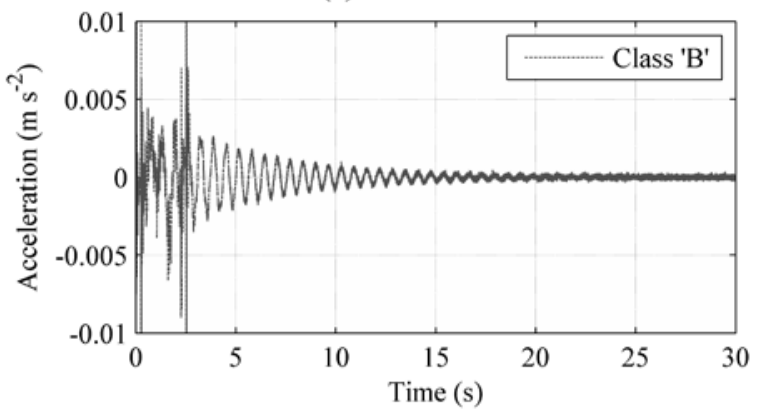

(d)

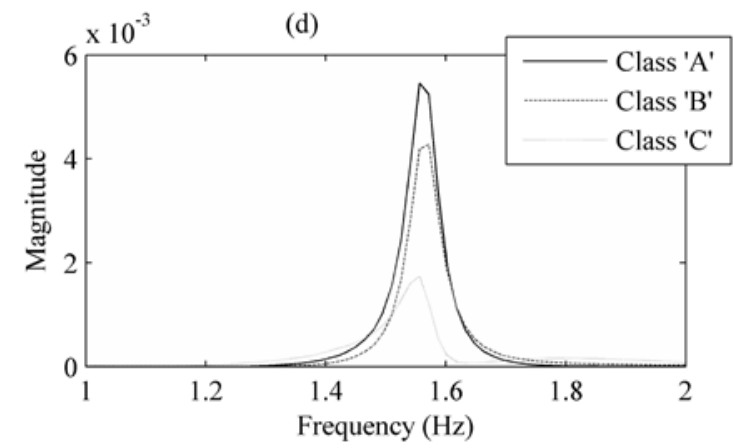

427

Fig. 11. Sensitivity of frequency detection to road profile. (a) signal from bridge pier with Class 'A' road surface, (b) signal from bridge pier with Class 'B' road surface, (c) signal from bridge pier with Class 'C' road surface, (d) frequency content of signals in (a) to (c).

\section{Identifying the presence of scour by analysing pier acceleration signals}

Fig. 12(a) shows the acceleration signal measured at the top of the bridge pier due to the passing vehicle for the three soil stiffness profiles considered for the case of zero scour. The vehicle traverses at $80 \mathrm{~km} \mathrm{hr}^{-1}$ over a Class 'A' road surface and the signals contain a SNR = 20. The three signals in Fig. 12(a) are difficult to distinguish so Fig. 12(b) shows only the first 10 seconds of data. Fig. 12(c) shows the frequency content of the signals shown in Fig. 12(a). From this figure, it is clear that it is possible to detect the first natural frequency of the bridge (which is lateral sway) for each of the soil stiffness profiles modelled. The difference in magnitude between each frequency peak is due to the relative stiffness of the soil impeding the lateral sway motion. The loose sand profile allows more movement than the dense sand 
444 loose sand.

(a)

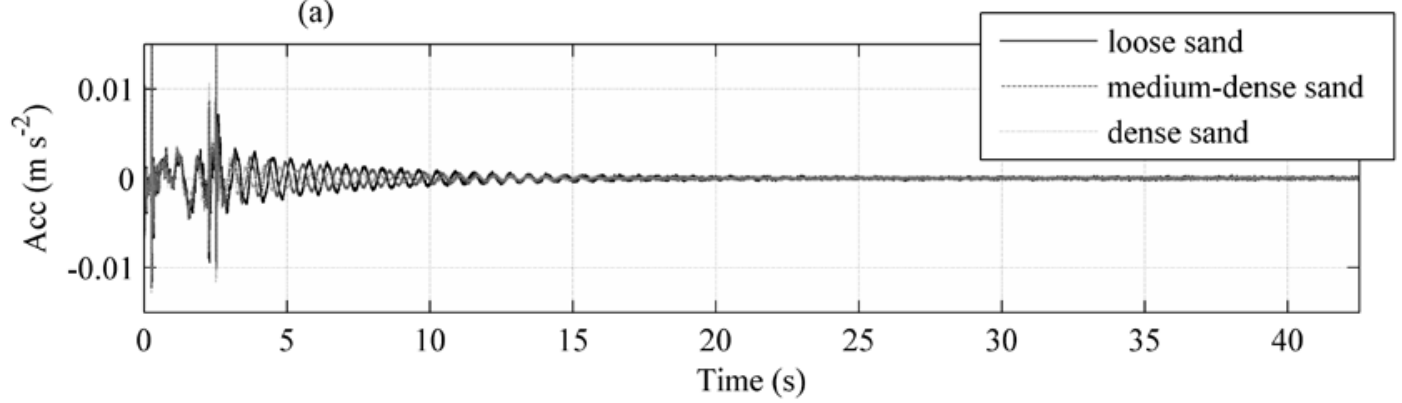

(b)
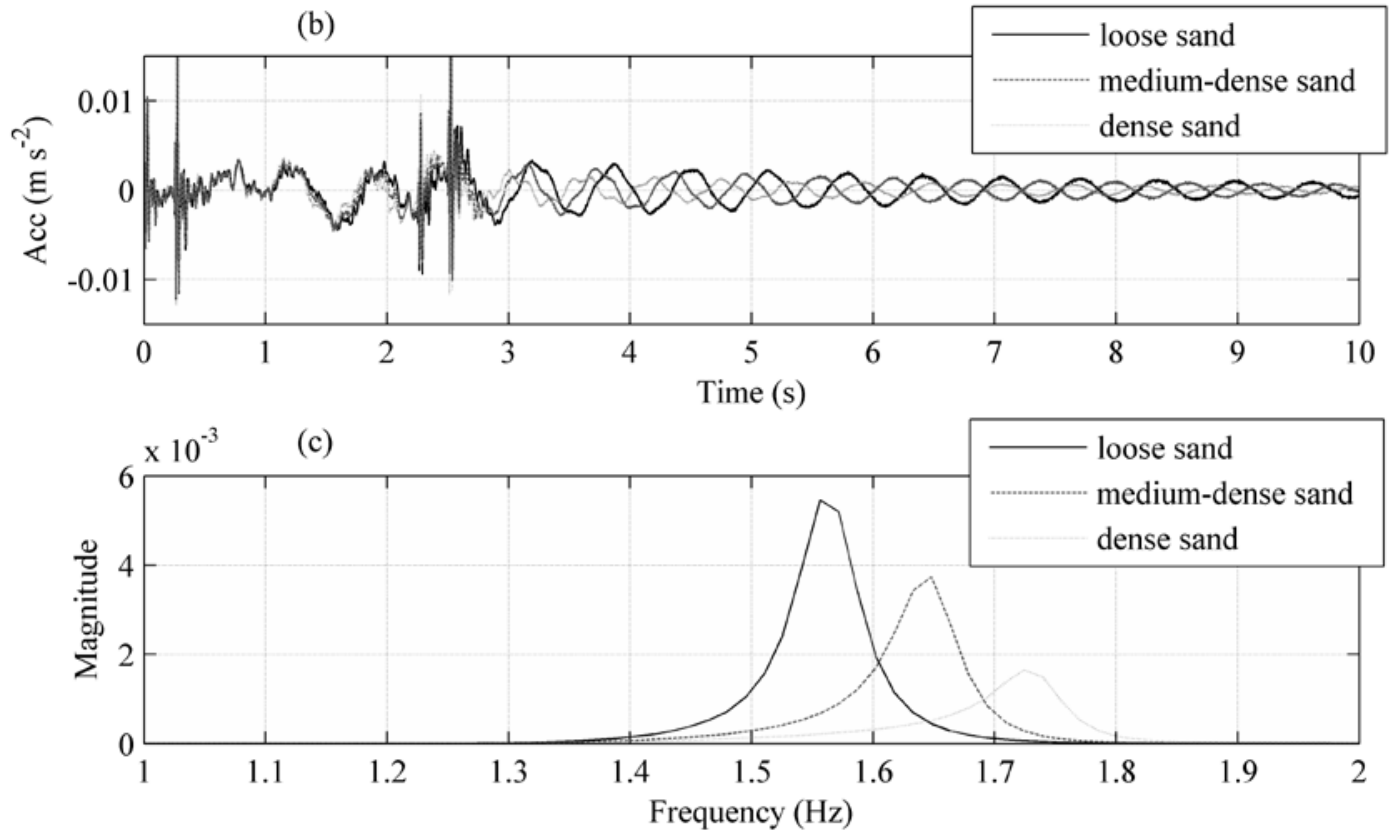

445

Fig. 12. Bridge response due to passing vehicle and subsequent free vibration. (a)

acceleration response from bridge pier for loose, medium-dense and dense sand profiles with 40 seconds of free vibration; (b) acceleration response from bridge pier for loose, mediumdense and dense sand profiles with 7.5 seconds of free vibration; (c) frequency response of

452 Fig. 12 demonstrates that the natural frequency of mode 1 can be accurately determined by analysing the acceleration response of the pier with a Fourier transform for all three soil 
454 densities. The next step is to induce scour in the analysis and observe the change in 455 frequency. An example of this analysis is shown in Fig. 13. The analysis involved running the 456 vehicle over the bridge to generate an acceleration signal at the top of the bridge pier and 457 adding noise. This signal was then analysed with a fast Fourier transform to determine the 458 frequency content of the signal. A scour depth of $10 \mathrm{~m}$ is induced by removing springs from 459 around the central pier foundation and the process is repeated to generate a scoured signal. 460 The solid and dashed plots in Fig. 13(a) shows the acceleration signals generated at the top of 461 the bridge pier for the case of zero scour and the $10 \mathrm{~m}$ scour depth respectively, (for a loose 462 sand profile). For ease of visualising the signals, Fig. 13(b) shows just the first 10 seconds of 463 the pier acceleration responses. On the left hand side of this plot, a total of four impulses in 464 the acceleration signals (between $t=0$ and $t=2.5 \mathrm{~s}$ ) are visible. This corresponds to the front 465 and rear axles entering and leaving the bridge. The front axle enters the bridge at $t=0 \mathrm{~s}$ and 466 the rear axle leaves the bridge at $t=2.5 \mathrm{~s}$. Fig. 13(c) shows the frequency content of the 467 signals shown in Fig. 13(a). It can be seen in Fig. 13(c) that the natural frequency for zero 468 scour was $1.556 \mathrm{~Hz}$. It can also be seen in Fig. 13(c) that the natural frequency at the 469 maximum scour depth of $10 \mathrm{~m}$ was $0.9308 \mathrm{~Hz}$. Therefore, a significant and measureable reduction in natural frequency was observed. 
(a)
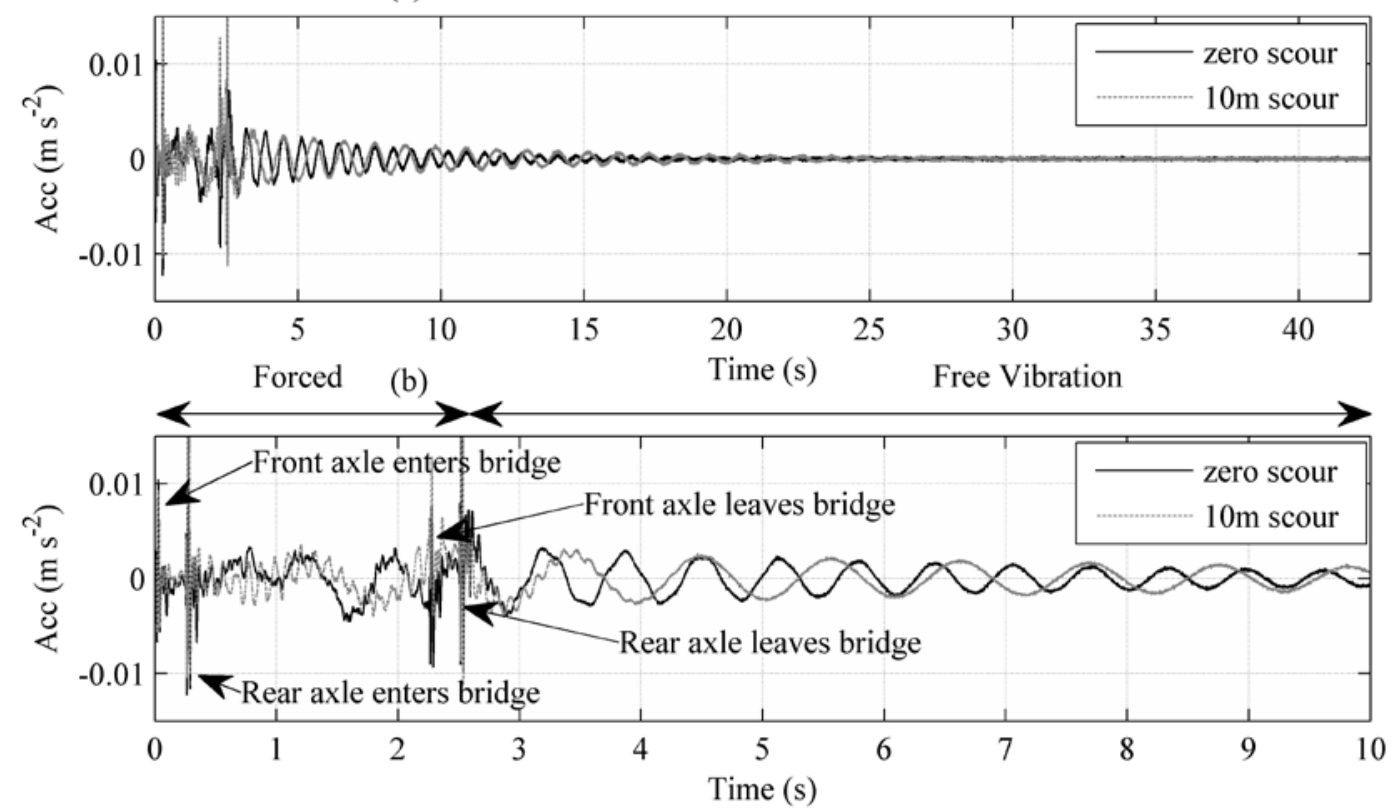

(c)

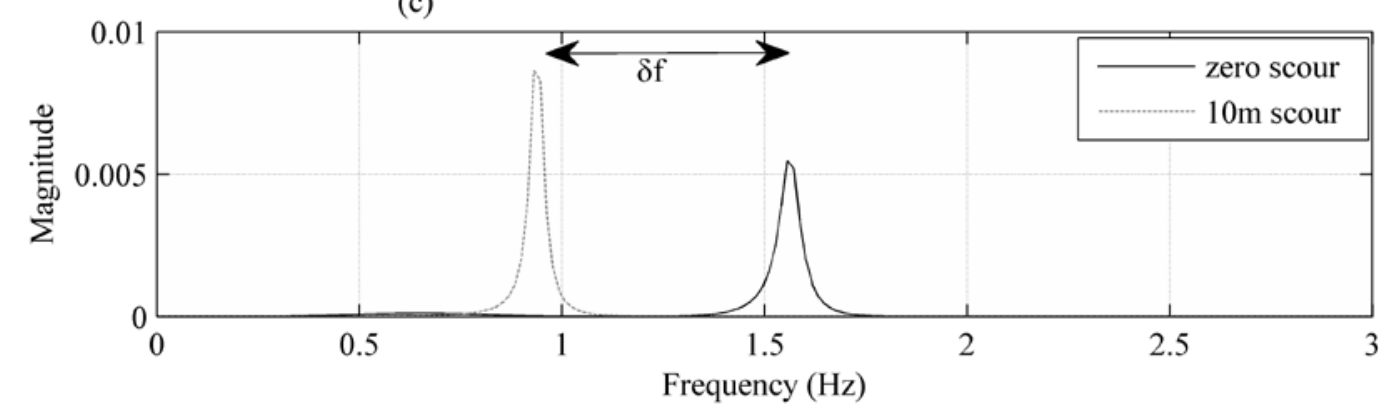

471

472

477 By repeating the analysis for scour depths ranging from $0.5 \mathrm{~m}$ to $10 \mathrm{~m}$, the natural frequency 478 for each scour depth was determined. Scour was induced around the central pier piled 479 foundation by removing springs iteratively from the model, this corresponds to an increase in 480

Fig. 13. Effect of $10 \mathrm{~m}$ of scour on the pier acceleration response for loose sand profile. (a) acceleration response (laterally) at top of bridge pier for zero and $10 \mathrm{~m}$ scour due to passage of vehicle, including 40 seconds of free vibration; (b)acceleration response of bridge pier with 7.5 seconds of free vibration; (c) frequency content of signals shown in (a). scour depth and a loss of associated soil stiffness. A spring is removed and the vehicle is rerun across the bridge to generate a new acceleration signal, which is analysed for its frequency content. The variation in natural frequency with scour depth for the 'loose sand' is 

shown by the solid plot with circular data markers in Fig. 14. Fig. 14 also shows the change 484 in the natural frequency plotted against the depth of scour for the 'medium-dense sand' and 485 'dense sand' stiffness profiles. It is clear from this figure that for the three soil stiffness profiles simulated, it was possible to detect a change in the natural frequency of the bridge 487 due to scour using vehicle induced vibrations. It is worth noting that the method was not sensitive to soil stiffness (loose, medium-dense or dense) i.e. for all soil densities considered, there is a clear reduction in natural frequency with increasing scour. Not surprisingly, the magnitude of the frequency for a given scour depth varies with the soil stiffness. However, the variation with soil stiffness is significantly less than the variation with scour depth. This basically implies that the increase in effective length resulting from scour had a much larger effect on the frequency response of the structure than changes in the stiffness of the soil 494 supporting the foundation.

495

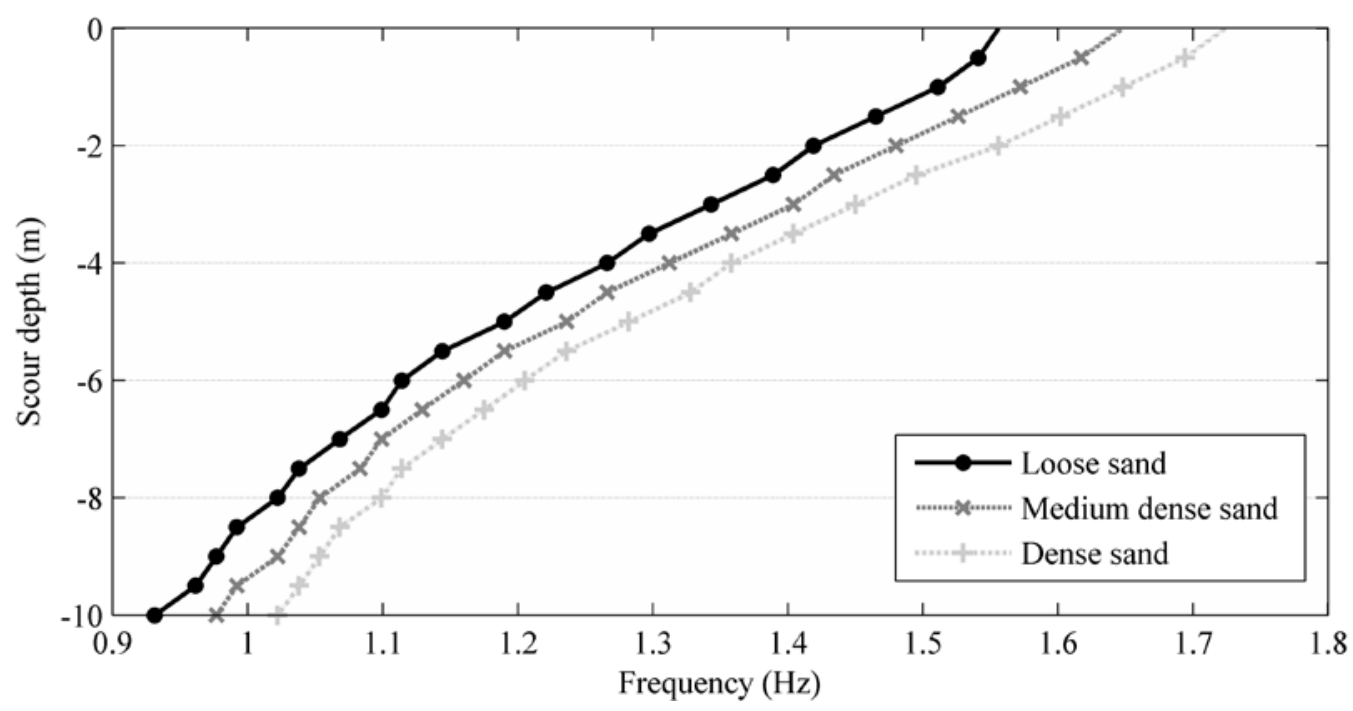

Fig. 14. Frequency change with scour for all three soil stiffness profiles. 
500 A field-validated model developed by the authors which is capable of tracking the change in the natural frequency of a single pile affected by scour was extended in this paper to consider the case of a full bridge subjected to traffic loading. A novel Vehicle-Bridge-Soil Interaction (VBSI) model was developed to explore the potential frequency changes due to scour of an integral bridge structure for a range of soil stiffnesses typically found in the field.

In the first instance, it was necessary to establish how scour affects the natural frequency of the bridge and if the changes in frequency would be sufficiently large to warrant further exploration of this method as a potential scour monitoring tool. A numerical modal study was conducted to address this question. The aim of this study was to assess the magnitude of frequency changes that can be expected for a typical bridge structure subjected to scour of the central piles. From this study, the expected magnitude of the frequency shift was established and deemed sufficiently large $(\approx 40 \%)$ to warrant an investigation into the feasibility of detecting scour by analysing the bridge's response to a moving vehicle. The VBSI model was used to generate realistic acceleration signals from the structure due to a two-axle truck passing at typical highway speeds $\left(80 \mathrm{~km} \mathrm{hr}^{-1}\right)$. The lateral acceleration response at the top of the bridge pier was analysed. Results indicate that for all three soil stiffness profiles modelled 516 (loose, medium-dense and dense sand) the response signals generated from this vehicular 517 loading are sufficient to allow the changes in natural frequency caused by scour to be detected. Moreover, the shape of the scour depth vs frequency plot was the same for all three soil stiffness profiles which shows that the method is not sensitive to soil stiffness.

520 Limitations in the analysis include the fact that only one type of vehicle was modelled, namely a two-axle truck. Therefore the conclusions of the present study may only be relevant for this vehicle type. Also, since the method relies on frequency changes of the bridge being detected to infer the presence of scour, this method would be sensitive to other forms of 
damage to the superstructure such as crack formation, thermal effects etc. Establishing the exact mechanism causing the changes in frequency requires further study, and is not addressed in this paper. The current paper serves as a feasibility study to detect the presence

527 of scour from vehicle-induced vibrations.

528 The method developed in this paper shows promise in terms of use as part of an infrastructure 529 management framework incorporating real-time low maintenance scour monitoring. The 530 advantage of the method is that it does not require complex underwater installations and negates the requirement for dangerous diving inspections to monitor scour. The results indicate that accelerometers fixed to the structure above the waterline may possibly be used as a continuous scour monitoring solution. Real-time analysis of signals from a structure of interest could be monitored for frequency changes or signals could be analysed before and after major flood events to attempt to detect losses of stiffness caused by scour. Whilst this appears promising, a full-scale application of the method on a real bridge is recommended as future work.

\section{Acknowledgements}

540 The authors would like to acknowledge the support of the Earth and Natural Sciences (ENS)

541 Doctoral Studies Programme, funded by the Higher Education Authority (HEA) through the 542 Programme for Research at Third Level Institutions, Cycle 5 (PRTLI-5), co-funded by the 543 European Regional Development Fund (ERDF), the European Union Framework 7 project 544 SMART RAIL (Project No. 285683) and the European Union H2020 project DESTination 545 RAIL (Project No. 636285).

\section{References}

548 Abdel Wahab, M. M., and De Roeck, G. (1999). “Damage Detection in Bridges Using Modal 

Curvatures: Application To a Real Damage Scenario.” Journal of Sound and Vibration, 226(2), 217-235.

551

552

553

554

555

556

557

558

559

560

561

562

563

564

565

566

567

568

569

570

571

572

573

Anderson, N. L., Ismael, A. M., and Thitimakorn, T. (2007). “Ground-Penetrating Radar : A Tool for Monitoring Bridge Scour.” Environmental \& Engineering Geoscience, XIII(1), $1-10$.

Avent, R. R., and Alawady, M. (2005). "Bridge Scour and Substructure Deterioration: Case Study.” Journal Of Bridge Engineering, 10(3), 247-254.

Briaud, J. L., Chen, H. C., Ting, F. C. K., Cao, Y., Han, S. W., and Kwak, K. W. (2001). “Erosion Function Apparatus for Scour Rate Predictions.” Journal of Geotechnical and Geoenvironmental Engineering, 105-113.

Briaud, J. L., Chen, H., Li, Y., Nurtjahyo, P., and Wang, J. (2005). “SRICOS-EFA Method for Contraction Scour in Fine-Grained Soils.” Journal of Geotechnical and Geoenvironmental Engineering, 131(10), 1283-1295.

Briaud, J. L., Hurlebaus, S., Chang, K., Yao, C., Sharma, H., Yu, O., Darby, C., Hunt, B. E., and Price, G. R. (2011). Realtime monitoring of bridge scour using remote monitoring technology. Security, Austin, TX.

Briaud, J. L., Ting, F., and Chen, H. C. (1999). "SRICOS: Prediction of Scour Rate in Cohesive Soils at Bridge Piers.” Journal of Geotechnical and Geoenvironmental Engineering, (April), 237-246.

Cantero, D., Gonzalez, A., and O’Brien, E. J. (2011). “Comparison of bridge dynamic amplification due to articulated 5-axle trucks and large cranes.” Baltic Journal of Road and Bridge Engineering, 6(1), 39-47.

Cebon, D. (1999). Handbook of Vehicle-Road Interaction. Swets \& Zeitlinger, Netherlands.

Chen, C.-C., Wu, W.-H., Shih, F., and Wang, S.-W. (2014). "Scour evaluation for foundation of a cable-stayed bridge based on ambient vibration measurements of superstructure.” 
575 Concast. (2014). “Concast Precast Group.” Civil Engineering Solutions, <http://www.concastprecast.co.uk/images/uploads/brochures/Concast_Civil.pdf> (May 1, 2014).

578

579

580

581

582

583

584

585

586

587

588

589

590

591

592

593

594

595

596

597

598

Doebling, S., and Farrar, C. (1996). Damage identification and health monitoring of structural and mechanical systems from changes in their vibration characteristics: $a$ literature review.

Dukkipati, R. V. (2009). Matlab for Mechanical Engineers. New Age Science.

Dutta, S. C., and Roy, R. (2002). “A critical review on idealization and modeling for interaction among soil-foundation-structure system.” Computers \& Structures, 80(2021), 1579-1594.

Elsaid, A., and Seracino, R. (2014). "Rapid assessment of foundation scour using the dynamic features of bridge superstructure.” Construction and Building Materials, Elsevier Ltd, 50, 42-49.

De Falco, F., and Mele, R. (2002). “The monitoring of bridges for scour by sonar and sedimetri.” NDT\&E International, 35, 117-123.

Farrar, C. R., Duffey, T. A., Cornwell, P. J., and Doebling, S. W. (1999). "Excitation methods for bridge structures.” Proceedings of the 17th International Modal Analysis Conference Kissimmee, Kissimmee, FL.

Fisher, M., Chowdhury, M. N., Khan, A. a., and Atamturktur, S. (2013). “An evaluation of scour measurement devices.” Flow Measurement and Instrumentation, Elsevier, 33, 5567.

Forde, M. C., McCann, D. M., Clark, M. R., Broughton, K. J., Fenning, P. J., and Brown, A. (1999). “Radar measurement of bridge scour.” NDT\&E International, 32, 481-492.

Foti, S., and Sabia, D. (2011). "Influence of Foundation Scour on the Dynamic Response of 
González, A. (2010). "Vehicle-Bridge Dynamic Interaction Using Finite Element Modelling.” Finite-Element Analysis, 637-662.

602

603

604

605

606

607

608

609

610

611

612

613

614

615

616

617

618

619

620

621

622

623

González, A., and Hester, D. (2013). “An investigation into the acceleration response of a damaged beam-type structure to a moving force.” Journal of Sound and Vibration, 332(13), 3201-3217.

Green, F., and Cebon, D. (1997). "Dynamic interaction between heavy vehicles and highway bridges.” Computers and Structures, 62(2), 253-264.

Hamill, L. (1999). Bridge Hydraulics. E.\& F.N. Spon, London.

Hester, D., and González, A. (2012). “A wavelet-based damage detection algorithm based on bridge acceleration response to a vehicle.” Mechanical Systems and Signal Processing, 28, 145-166.

Ju, S. H. (2013). "Determination of scoured bridge natural frequencies with soil-structure interaction.” Soil Dynamics and Earthquake Engineering, 55, 247-254.

Klinga, J. V., and Alipour, A. (2015). “Assessment of structural integrity of bridges under extreme scour conditions.” Engineering Structures, Elsevier Ltd, 82, 55-71.

Kwon, Y. W., and Bang, H. (2000). The Finite Element Method using MATLAB. CRC Press, Inc., Boca Raton, FL.

Lagasse, P. F., Schall, J. D., Johnson, F., Richardson, E. V., and Chang, F. (1995). Stream stability at highway structures. Washington, DC.

Lyons, R. (2011). Understanding digital signal processing. Prentice Hall, Boston, MA.

El Madany, M. (1988). "Design and optimization of truck suspensions using covariance analysis.” Computers \& structures.

Melville, B. W., and Coleman, S. E. (2000). Bridge scour. Water Resources Publications, Highlands Ranch, CO. 
Prendergast, L. J., and Gavin, K. (2014). “A review of bridge scour monitoring techniques.” Journal of Rock Mechanics and Geotechnical Engineering, 6(2), 138-149.

Prendergast, L. J., and Gavin, K. (2016a). “A comparison of initial stiffness formulations for small-strain soil - pile dynamic Winkler modelling.” Soil Dynamics and Earthquake Engineering, 81, 27-41.

Prendergast, L. J., Gavin, K., and Doherty, P. (2015). “An investigation into the effect of scour on the natural frequency of an offshore wind turbine.” Ocean Engineering, 101, 111.

Prendergast, L. J., Hester, D., and Gavin, K. (2016b). “Development of a Vehicle-Bridge-Soil Dynamic Interaction Model for Scour Damage Modelling.” Shock and Vibration, 2016.

Prendergast, L. J., Hester, D., Gavin, K., and O’Sullivan, J. J. (2013). “An investigation of the changes in the natural frequency of a pile affected by scour.” Journal of Sound and Vibration, 332(25), 6685-6702.

Sampaio, R. P. C., Maia, N. M. M., and Silva, J. M. M. (1999). “Damage Detection Using the Frequency-Response-Function Curvature Method.” Journal of Sound and Vibration, 226(5), 1029-1042.

Shirole, A. M., and Holt, R. C. (1991). "Planning for a comprehensive bridge safety assurance program.” Transport Research Record, Transport Research Board, Washington, DC, 137-142.

Wardhana, K., and Hadipriono, F. C. (2003). “Analysis of Recent Bridge Failures in the United States.” Journal of Performance of Constructed Facilities, 17(3), 144-151.

Winkler, E. (1867). Theory of elasticity and strength. Dominicus Prague.

Yang, F., and Fonder, G. (1996). “An iterative solution method for dynamic response of bridge-vehicles systems.” Earthquake engineering \& structural dynamics, 25, 195-215.

Yang, Y., Yau, J., and Wu, Y. (2004). Vehicle-bridge interaction dynamics. 
649 Yankielun, N., and Zabilansky, L. (1999). "Laboratory Investigation of Time-Domain 650 Reflectometry System for Monitoring Bridge Scour.” Journal of Hydraulic Engineering, 651 125(12), 1279-1284.

652 Yu, X. (2009). “Time Domain Reflectometry Automatic Bridge Scour Measurement System: 653 Principles and Potentials.” Structural Health Monitoring, 8(6), 463-476.

654 Zarafshan, A., Iranmanesh, A., and Ansari, F. (2012). "Vibration-Based Method and Sensor 655 for Monitoring of Bridge Scour.” Journal Of Bridge Engineering, 17(6), 829-838.

656 